Research Article

\title{
Evolution Dynamics of Agricultural Internet of Things Technology Promotion and Adoption in China
}

\author{
Fang $W u \mathbb{D}^{1,2}$ and Junhai Ma $\mathbb{D}^{1}$ \\ ${ }^{1}$ Complex Dynamics Research Group, College of Management and Economics, Tianjin University, Tianjin 300072, China \\ ${ }^{2}$ College of Computer and Information Engineering, Tianjin Agricultural College, Tianjin 300381, China \\ Correspondence should be addressed to Junhai Ma; mjhtju@aliyun.com
}

Received 9 March 2020; Revised 24 May 2020; Accepted 23 June 2020; Published 6 August 2020

Academic Editor: Youssef N. Raffoul

Copyright (c) 2020 Fang Wu and Junhai Ma. This is an open access article distributed under the Creative Commons Attribution License, which permits unrestricted use, distribution, and reproduction in any medium, provided the original work is properly cited.

\begin{abstract}
Internet of Things is the core technology of smart agriculture and can reform and upgrade traditional agriculture for reducing cost, reducing pollution, and increasing productivity and quality in China. From government-led and market economy perspectives, promotion mechanisms and sustainable adoption of agricultural Internet of Things technology are analyzed. In the initial application phase, the promotion of Internet of Things requires government support. For investigating the relationship between the government and farmers, this study builds an evolutionary game model and finds that increases of cost subsidy, farmers' negative feedback, government's positive feedback, and chemical agriculture cost can make the model evolve toward the strategy set: farmer adoption and government support. For long-term development, a sustainable model in competitive market is built by competition game and exponential replication equation. This paper analyzes the equilibrium of adoption ratio, long-run profit, and the conversion between equilibrium points under capacity sharing strategy in competitive market. It is also found that the market will eventually evolve to the technology selection strategy whose long-run average profit dominates the market. The innovations are that evolutionary game is used for analyzing the initial stage and competitive game and asynchronous update mechanism are used for analyzing the sustainable development adoption. At last, references are provided for agricultural Internet of Things development policy from the perspectives of initial promotion and long-run sustainability.
\end{abstract}

\section{Introduction}

In China, chemical agriculture caused double negative externalities: "quality risk of agricultural products and pollution of ecological environment" [1]. The traditional production method can no longer adapt to the trend of green agriculture.

By agricultural Internet of Things (IoT), relevant agricultural data such as environmental conditions, growth status, soil status, irrigation water, pest and fertilizers, weed management, and greenhouse production environment are collected and are transmitted by Wi-Fi, Global System for Mobile Communications, or Bluetooth, and finally the process monitoring and scientific decision are achieved through intelligent terminals for improving crop yields, reducing costs and optimizing process inputs [2]. The process is shown in Figure 1.
Agricultural IoT is the core of smart agriculture technology and provides a transformation opportunity from traditional chemical agriculture to green agriculture. Agricultural IoT can reduce the use of pesticide and improve agricultural productivity. For example, the intelligent warning technology of vegetable disease is one of the typical applications about agricultural IoT. The traditional vegetable production model relies on pesticides for pest control. In order to increase output and suppress disease, some farmers spray pesticides regularly or even in advance. These behaviors lead to soil pollution and vegetable safety crisis. Using vegetable disease warning technology, the vegetable growth information is collected by sensors for achieving disease identification and treatment. This method greatly reduces the use of pesticide and fertilizer and promotes a shift from the chemical-based production model to a green-smart production model. 


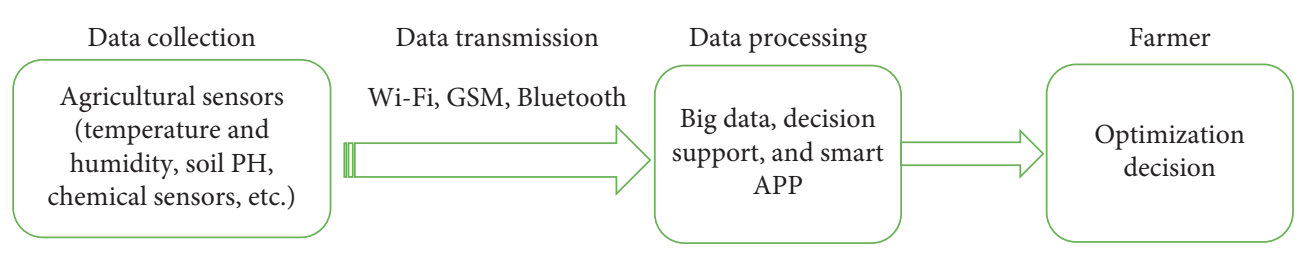

FIgURE 1: The Internet of Things (IoT).

In some countries, agricultural IoT has been sufficiently developed. The United States has become the country with the highest level of smart agricultural applications in the world. In the United Kingdom, Germany, Japan, Netherlands, and Israel, applications of agricultural IoT have reached the world's advanced level for coping with labor shortages, increasing productivity and increasing the degree of green agriculture [3-5]. For example, Israel uses agricultural IoT technology to create miracles in water-scarce deserts and has become an important exporter of fruits, vegetables, and flowers worldwide [6].

China is in a transition period from traditional agriculture to modern smart agriculture [7]. In Shanghai, Beijing, and Tianjin in China, governments have launched demonstration and experimentation on the promotion of the agricultural Internet of Things [8]. But in other regions of China, the development of agricultural IoT faces the following difficulties. (1) Insufficient promotion of government. The government investment in agricultural IoT projects is necessary in initial application stage. However, due to weak understanding of farmer on technology, the utilization efficiency of support fund is low, and some agricultural IoT demonstration projects have become surface decorations [9]. (2) Unhealthy development model. Existing agricultural IoT projects rely on government support. Due to high cost of IoT equipment and low profit of agriculture, small-scale farmers are conservative in IoT technology adoption $[9,10]$. The mode of relying on government is not a healthy and sustainable development route in the long run. How to promote the adoption level of agricultural Internet of Things in competitive market is an urgent issue to be studied.

For the first problem, it is necessary to further analyze the interaction relation between government subsidy and farmer's adoption behavior. For the second problem, it is necessary to build a sustainable business model that is dominated by farmers and obeys market competition rule. And capacity sharing is an effective way to achieve balanced and coordinated development of IoT adoption.

This paper will use the evolutionary game model for analyzing the conflicts of interest between government and farmers, investigating the evolution toward sustainable adoption. And we use the dynamic differential game model describing competition and technology selection for exploring the long-term sustainable development mechanism.

\section{Literature Review}

There are three streams of literatures related to this research: the relation between government promotion and technology adoption; the dynamic evolution of technology choice; and the complex volatility characteristics of competitive markets.

2.1. The Relation between Government Support Policies and Technology Adoption. Government support is a key process for commercializing new technologies. Xia et al. believed that the key to promoting adoption was to identify obstacles in the promotion process, and the government provided the support to overcome those obstacles [11]. From a technology diffusion viewpoint, Yuan and Yang [12] analyzed the influential factors of adopting building information modeling (BIM) under government support by game theory and found that government subsidies could improve the attitude and adoption level of BIM. Taking the province of Foggia, Italy, as an example, Lucia and Pazienza [13] analyzed impacts of taxes, subsidies, and expanded producer responsibilities on the reduction of plastic. The result showed that the types of plastic waste were sensitive to the government policies. Based on a Stackelberg game model followed by government-led dairy farms, Zhao and You [14] built an optimal design of waste-to-energy incentive policy for farms' adoption of anaerobic digesters and biopower generation technology. Sara et al. [15] built an evolutionary game model composed of government, producers, and consumers and found that public regulation, government incentives for producers, and synergy between producers and consumers were necessary to promote electric vehicles. Zhao and Liu [16] analyzed the conflicts of interest between the government and traditional power companies in use of carbon capture and storage (CCS). And an evolutionary game model was established; the stability and evolution process of the model were discussed. It was found that strengthening government supervision, encouraging technology adoption, and reducing supervision costs and technology adoption costs can promote technology diffusion. Shi et al. [17] simulated the enterprise's response to the government's policy of promoting low-carbon technology and found the following: although carbon taxes, subsidies, and fines can promote technology diffusion, these measures were ineffective or even harmful to low-carbon companies.

From the above studies, we can see that there is a close relationship between government support and technology diffusion. As far as we know, there is a lack of analysis on the promotion of agricultural IoT technology in the existing research. In agriculture, although Internet of Things technology holds the promise of greatly transforming and upgrading traditional agriculture in developing countries, its widespread adoption is still a challenging and urgent problem. Due to high equipment cost and low farmers' 
awareness level, if the government does not promote agriculture IoT, farmers' production technology will be locked in the traditional chemical agricultural production mode. What regulation measures can break through the locking effect of traditional agricultural technology is a problem that should be studied. Above literatures provide method reference for this research.

\subsection{The Dynamic Evolution of Strategy Choice Described by} Exponential Replication Equation. Some scholars have already started the research on strategy choice evolution by asynchronous update mechanism. Kopel et al. constructed a production competition model composed of a profitmaximizing company and a company that paid attention to the society and used asynchronous update mechanism to analyze the impact of endogenous choices on the long term. It was found that companies considering a profit combination and consumer welfare had greater market share than other competitors [18]. Considering two behavior rules, namely, local monopoly approximation and gradient dynamics, Baiardi et al. built an evolutionary model of oligopoly competition in which agents could choose different behavior rules to make production decisions. And the global dynamic properties of the model under the evolution of different behavioral rules were analyzed [19]. Based on synchronous update dynamics, Bischi et al. analyzed a time evolution model of a population participant in which players facing the binary selection game, the equilibrium state, and local and global dynamics characteristics were investigated [20]. Lamantia and Radi constructed an evolutionary game model where the company could choose between two linear production technologies. The system characteristics were analyzed by piecewise smoothing graphs, the local and global dynamic characteristics of the model were studied, and the economic significance of the attractor was discussed [21].

Above literature studied the dynamic evolution of strategy choice by the asynchronous update mechanism. As far as we know, there is almost no literature on the technology choice of agricultural IoT. This study will use this mechanism to analyze the dynamic fluctuations of choice proportion about agricultural IoT technology in the competitive market.

2.3. Complex Dynamics of the Market. In competitive market, due to seasonal change, technology upgrade or policy shocks, drastic output, and price changes can cause market's complex fluctuations, such as periodic oscillation and random chaotic fluctuations. In response to the complex dynamics of competitive market, $\mathrm{Wu}$ and $\mathrm{Ma}$ [22] analyzed the stability of Nash equilibrium in epiphytic competitive market and investigated routes to periodic and chaotic random fluctuations. Naimazada and Tramontana [23] built a triopoly game model with nonlinear demand function and found that when Nash equilibrium lost stability, the competitive market entered into complex dynamics that was characterized by random chaotic fluctuations. Hommens et al. [24] investigated the effect of increasing players in oligopoly evolutionary competition model and found that increasing firms' number could make Nash equilibrium unstable. Ahmad and Marina [25] analyzed the existence of equilibrium for an exchange economy evolutionary model. Askar et al. [26] investigated the Nash equilibrium and chaos fluctuations in a game model constructed by three competitive firms, and the firm's preference was derived from constant elasticity of substitution (CES) production function. Yu et al. [27] constructed a 3D Hotelling price discrete dynamic model, analyzed the influence of important parameters on the model equilibrium, and described the chaotic behavior of the system through numerical simulation. Garmani et al. [28] analyzed the price game of limited rational duopoly content providers, and one of the players used smooth information to adjust the price strategy. The chaos phenomenon and the balance of the game were analyzed, and the appropriate control method was used to control chaos. Zhou and Wang [29] constructed a profit-maximizing game model for $R \& D$ competition, analyzed the stability of Nash equilibrium, and found that highly efficient innovative companies can benefit from chaos. Ma et al. [30] built a supply chain system consisting of customers, government, electric companies, and fuel vehicles and found that subsidies may destroy the stability of the system, making the supply chain uncontrollable, and the Stackelberg pricing strategy with delay characteristics was more suitable for system operation management.

Above scholars studied complex fluctuations of output or price in various markets. However, different economic models have different complex dynamic characteristics. In this article, this issue will be discussed: how do complex dynamics affect the level of technology adoption in competitive market?

Based on above research vacancies, the structure of the article is organized as follows. In Sections 3 and 4, considering initial application status, the relationship between government strategy and farmer adoption is analyzed and both parties' interest mechanism is investigated. The first type of research (Section 2.1) can provide method references. In Section 5, for the long-term and sustainable development of agricultural Internet of Things, a dynamic adoption competition model is constructed based on synchronous update mechanism for exploring ways to increase technology adoption proportion. The second type of literature (Section 2.2) provides a reference for investigating dynamic adoption, and the third part literature (Section 2.3) about competitive complexity provides the theoretical basis for building a dynamic competitive model. Section 6 is the conclusion. The article structure is shown in Figure 2. 


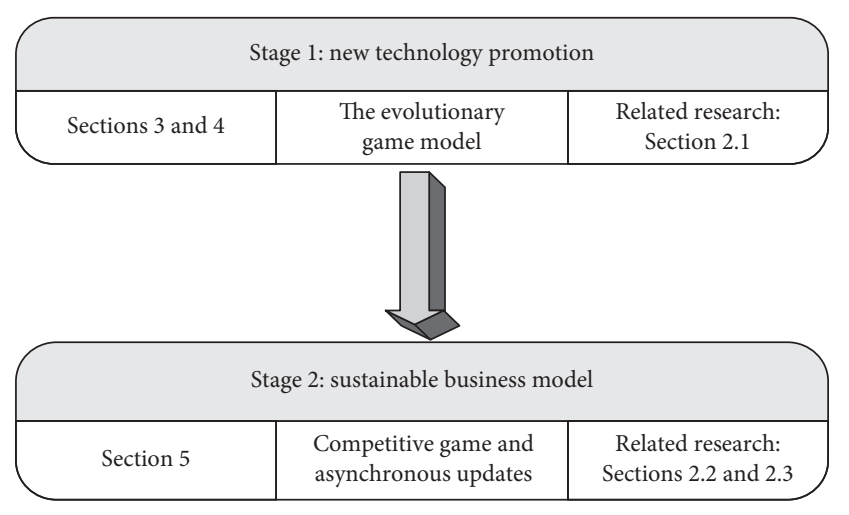

FIgURE 2: The article structure diagram.

\section{The Strategic Evolution between the Government and Farmers}

\subsection{Assumptions and Notations}

(1) Vegetable farmer and the government are a pair of players. Under government's supervision and support, vegetable farmer chooses to adopt IoT vegetable warning technology or not. Assuming the local government sets strict supervision standards, rejecting IoT technology will lead to excessive pesticide, and thus the farmer will be punished.

Farmer's strategic selection space is \{using intelligent warning platform of vegetable disease; using traditional diagnosis and treatment methods which is relying on pesticide and fertilizer\}; the government's strategic selection space is supervision; no supervision\}.

(2) The income of farmer adopting (or rejecting) IoT technology is $I_{1}$ (or $I_{2}$ ). If farmer adopts IoT disease warning technology, the profit rate is $I_{1}$. The fixed $\operatorname{cost} c_{1}$ includes agricultural sensors, such as temperature and humidity sensors, soil sensors, network equipment, and early warning terminals which are based on intelligent computing. Through above equipment, early warning can be given before vegetable diseases occur. Agricultural IoT technology is conducive to improving the output, quality, and safety of vegetables. However, due to the weak integration between IoT and agriculture, agricultural IoT devices are rare and expensive.

The government gives subsidies to farmers for technology upgrade, and the subsidy is $\alpha_{2} c_{1} ; \alpha_{2}$ is the subsidy ratio. In practice, in China, for improving agriculture, government invests in purchasing IoT equipment for farmers, and farmers only pay for system maintenance.

For farmer who refuses IoT technology, if the government finds that the pesticide dose exceeds the standard, the farmer will be fined: the fine is $\beta I_{2}$. The dose cost of pesticides invested by farmer is $c_{N}$.
(3) If farmers adopt IoT vegetable disease warning technology, the superior government will give the local government payment $R_{s}$, and the local government will allocate the payment. If farmers reject technology, the local government will not receive fund from superior government. The cost of government supervision is $c_{3}$. The local government gives subsidies to farmers who adopt technology, including cost subsidies and tax subsidies. The cost subsidy is $\sigma R_{s}=a_{2} c_{1}$; the tax for adopting IoT technology is $r \varepsilon I_{1}(0<\gamma<1)$, and the tax for nonadoption is $\varepsilon I_{2}$.

(4) When the dose of pesticide exceeds the standard, the farmer's credibility is lost, and negative feedback appears, such as loss of existing and potential customers. The negative feedback value of the farmer is perceived as $-v_{F}$. When the government implements strict supervision, high-quality products meet consumer demand, and the economy moves forward; the value of positive feedback of government regulators is $v_{G}$.

(5) All parameters are greater than zero, as shown in Table 1.

3.2. The Evolutionary Game Model. Table 2 shows the evolution matrix of two players in the game. The probability of choosing IoT disease warning technology is $\eta$, and the probability of rejecting is $1-\eta$. The government can choose strict supervision and no supervision. The supervision items include pesticide residues in vegetables, soil pollution, etc. The probability of government supervision is $\mu$, and the probability of nonregulation is $1-\mu$.

3.3. The Expected Function of Farmer's Income. Equation (1) is the expected revenue of farmer adopting disease warning technology. Equation (2) is the expected revenue of nonadoption.

$$
\begin{aligned}
E_{\text {adoption }}= & \mu\left(\alpha_{1} I_{1}-c_{1}+\alpha_{2} c_{1}+c_{2}-\gamma \in I_{1}\right) \\
& +(1-\mu)\left(\alpha_{1} I_{1}-c_{1}+c_{2}-\epsilon I_{1}\right), \\
E_{\text {non-adoption }}= & \mu\left[\left(\alpha_{1}-\beta-\varepsilon\right) I_{2}-c_{N}-v_{F}\right] \\
& +(1-\mu)\left(\alpha_{1} I_{2}-\epsilon I_{2}-c_{N}-v_{F}\right) .
\end{aligned}
$$

So, the expected function of farmer's income is as follows:

$$
\begin{aligned}
E_{\text {farmer }}= & \eta E_{\text {adoption }}+(1-\eta) E_{\text {non-adoption }} \\
= & \eta\left[\mu\left(c_{2}-c_{1}+I_{1} \alpha_{1}+\alpha_{2} c_{1}-I_{1} \varepsilon \gamma\right)\right. \\
& \left.+(\mu-1)\left(c_{1}-c_{2}-I_{1} \alpha_{1}+I_{1} \varepsilon\right)\right] \\
& -(\eta-1)\left\{(\mu-1)\left(c_{N}+v_{F}-I_{2} \alpha_{1}+I_{2} \varepsilon\right)\right. \\
& \left.-\mu\left[c_{N}+v_{f}+I_{2}\left(\beta-\alpha_{1}+\varepsilon\right)\right]\right\} .
\end{aligned}
$$

The replication dynamic equation of farmer adoption is 
TABle 1: Notations.

\begin{tabular}{|c|c|c|}
\hline & Variable name & Explanation \\
\hline \multirow{9}{*}{$\begin{array}{l}\text { Adopting intelligent vegetable early warning } \\
\text { technology }\end{array}$} & $I_{1}=q_{1} p$ & Total revenue \\
\hline & $q_{1}$ & Output \\
\hline & & Product price \\
\hline & $\alpha_{1}$ & Profit ratio \\
\hline & $\alpha_{1} I_{i}, i=1,2$ & Profit \\
\hline & $c_{1}$ & Fixed cost of new technology \\
\hline & $\alpha_{2} c_{1}$ & Cost subsidy given by the government \\
\hline & & Cost savings of adopting new technology \\
\hline & $f=\beta I_{2}, \beta \in(0,1)$ & Penalty for overuse of pesticides \\
\hline \multirow{3}{*}{$\begin{array}{l}\text { Using traditional diagnosis and treatment methods } \\
\text { relying on pesticides }\end{array}$} & $I_{2}=q_{2} p$ & Total revenue of refusing IoT technology $\left(I_{1}>I_{2}\right)$ \\
\hline & $c_{N}$ & Pesticide input cost of traditional technology \\
\hline & $-v_{F}$ & The negative feedback \\
\hline \multirow{7}{*}{ Government } & $c_{3}$ & The supervision cost \\
\hline & $R_{s}$ & The payment from superior government \\
\hline & $\sigma R_{s}=\alpha_{2} c_{1}, \sigma \in(0,1]$ & $\begin{array}{l}\text { The subsidies of local government for farmers who } \\
\text { adopt technology }\end{array}$ \\
\hline & $\gamma \varepsilon I_{1}, \gamma \in(0,1]$ & Preferential tax of adoption under supervision \\
\hline & $\varepsilon I_{2}$ & Nonadopted tax of nonsupervision \\
\hline & $\varepsilon I_{1}$ & Unsupervised tax $\left(\alpha_{1}>\varepsilon\right)$ \\
\hline & $v_{G}$ & The positive feedback \\
\hline
\end{tabular}

TABle 2: The evolutionary game matrix.

\begin{tabular}{|c|c|c|}
\hline \multirow{2}{*}{ Government } & \multicolumn{2}{|c|}{ Farmer } \\
\hline & Adoption $(\eta)$ & Nonadoption $(1-\eta)$ \\
\hline Supervision $(\mu)$ & $\begin{array}{l}P_{F}=\alpha_{1} I_{1}-c_{1}+\alpha_{2} c_{1}+c_{2}-\gamma \varepsilon I_{1} \\
P_{G}=(1-\sigma) R_{s}-c_{3}+\gamma \varepsilon I_{1}+v_{G}\end{array}$ & $\begin{array}{l}P_{F}=\left(\alpha_{1}-\beta-\varepsilon\right) I_{2}-c_{N}-v_{F} ; \\
P_{G}=\varepsilon I_{2}+\beta I_{2}-c_{3}\end{array}$ \\
\hline Nonsupervision $(1-\mu)$ & $\begin{array}{l}P_{F}=\alpha_{1} I_{1}-c_{1}+c_{2}-\varepsilon I_{1} \\
P_{G}=R_{s}+\varepsilon I_{1}+v_{G}\end{array}$ & $\begin{array}{l}P_{F}=\alpha_{1} I_{2}-\varepsilon I_{2}-c_{N}-v_{F} \\
P_{G}=\varepsilon I_{2}-v_{G}\end{array}$ \\
\hline
\end{tabular}

$$
\begin{aligned}
F(\eta)= & \frac{\mathrm{d} \eta}{\mathrm{d} t}=\eta\left(E_{\text {adoption }}-E_{\text {farmer }}\right) \\
= & -\eta(\eta-1)\left(c_{2}-c_{1}+c_{N}+v_{f}+I_{1} \alpha_{1}-I_{2} \alpha_{2}-I_{1} \varepsilon\right. \\
& \left.+I_{2} \varepsilon+I_{2} \beta \mu+I_{1} \varepsilon \mu+\alpha_{2} c_{1} \mu-I_{1} \varepsilon \gamma \mu\right) .
\end{aligned}
$$

3.3.1. The Stable State of the System. Let the replication dynamic equation equal to $0(F(\eta)=0)$; we can get $\eta^{*}=0$ or 1 , and $\mu^{*}=\left(c_{1}+c_{2}-c_{N}-v_{f}-I_{1} \alpha_{1}+I_{2} \alpha_{1}+I_{1} \varepsilon-I_{2} \varepsilon\right) / I_{2} \beta+$ $I_{1} \varepsilon+\alpha_{2} c_{1}-I_{1} \varepsilon \gamma$. That means when the government supervision probability $\mu=\mu^{*}$, farmer's adoption probability $\eta$ is equal to any value in $[0,1]$. So, when $\mu=\mu^{*}$, the replication dynamic model is steady. Farmers have no incentive to change their current adoption strategy. The evolution phase diagram is shown in Figure 3.

When $\mu \neq \mu^{*}, \eta^{*}=0$, and $\eta^{*}=1$, namely, $\left(\mu \neq \mu^{*}, \eta^{*}=\right.$ $0)$ and $\left(\mu \neq \mu^{*}, \eta^{*}=1\right)$, both sets of parameters can make $F(\eta)=0$. So, $\mu \neq \mu^{*}, \eta^{*}=0$ and $\mu \neq \mu^{*}, \eta^{*}=1$ are all stable states of the system.

3.3.2. Summary of Evolutionary Paths. The stability strategy of the evolutionary game needs to be satisfied:

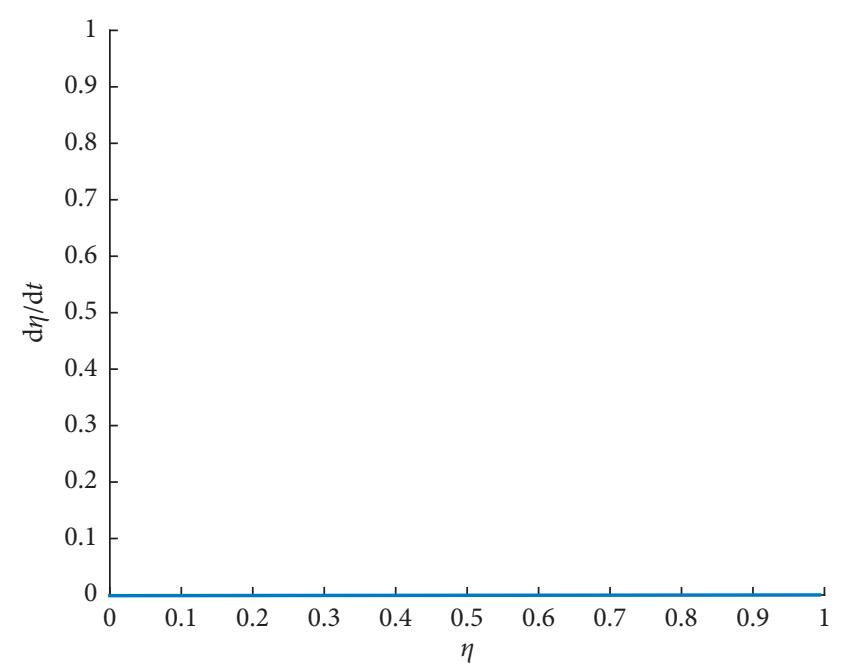

FIgURE 3: The evolution phase diagram of $\mu=\mu^{*}$.

$$
\left\{\begin{array}{l}
F(\eta)=\frac{\mathrm{d} \eta}{\mathrm{d} t}=0, \\
\frac{\mathrm{d}(F(\eta))}{\mathrm{d} \eta}<0,
\end{array}\right.
$$

where 


$$
\begin{aligned}
&\left.\frac{\mathrm{d}[}{\mathrm{d} \eta}(\eta)\right] \\
&=-(2 \eta-1)\left(c_{2}-c_{1}+c_{N}+v_{F}+I_{1} \alpha_{1}-I_{2} \alpha_{1}\right. \\
&\left.-I_{1} \varepsilon+I_{2} \varepsilon+I_{2} \beta \mu+I_{1} \varepsilon \mu+\alpha_{2} c_{1} \mu-I_{1} \varepsilon \gamma \mu\right) \\
&= \mu(1-2 \eta)\left(I_{2} \beta+I_{1} \varepsilon+\alpha_{2} c_{1}-I_{1} \varepsilon \gamma\right) \\
&-(1-2 \eta)\left(c_{1}-c_{2}-c_{N}-v_{F}-I_{1} \alpha_{1}+I_{2} \alpha_{1}+I_{1} \varepsilon-I_{2} \varepsilon\right) \\
&=(1-2 \eta)\left[\mu\left(I_{2} \beta+I_{1} \varepsilon+\alpha_{2} c_{1}-I_{1} \varepsilon \gamma\right)\right. \\
&\left.-\left(c_{1}-c_{2}-c_{N}-v_{F}-I_{1} \alpha_{1}+I_{2} \alpha+I_{1} \varepsilon-I_{2} \varepsilon\right)\right] \\
&=(1-2 \eta)\left[\mu\left(I_{2} \beta+I_{1} \varepsilon+\alpha_{2} c_{1}-I_{1} \varepsilon \gamma\right)-A\right],
\end{aligned}
$$

in which $A=c_{1}-c_{2}-c_{N}-v_{F}-I_{1} \alpha_{1}+I_{2} \alpha_{1}+I_{1} \varepsilon-I_{2} \varepsilon$.

Because the evolution stability strategy needs to satisfy $\mathrm{d}(F(\eta)) / \mathrm{d} \eta<0$, different situations of $\mu\left(I_{2} \beta+I_{1} \varepsilon+\alpha_{2} c_{1}-\right.$ $\left.I_{1} \varepsilon \gamma\right)-A$ need to be discussed:

(1) When $\quad \mu<A /\left(I_{2} \beta+I_{1} \varepsilon+\alpha_{2} c_{1}-I_{1} \varepsilon \gamma\right), \quad$ for $\left\{\begin{array}{l}F(0)=0 \\ F^{\prime}(0)<0\end{array}, \eta=0\right.$ is the evolutionary stable strategy. When government supervision probability $\mu<A$ / $\left(I_{2} \beta+I_{1} \varepsilon+\alpha_{2} c_{1}-I_{1} \varepsilon \gamma\right)$, farmer will refuse to choose vegetable disease warning technology $(\eta=0)$. Even if farmers purchase software and hardware under government's financial support, after several strategy adjustments, farmers will eventually give up the technology. The equipment is idle and the resources are wasted. In fact, this happened in China. The government has funded or even replaced farmers to purchase agricultural IoT equipment. However, some farmers abandoned the equipment after a short time and turned to the traditional chemical agriculture technology again. Therefore, it is concluded that the government should continue to increase the monitoring of chemical agriculture and encourage agricultural IoT projects.

The evolution phase diagram is shown in Figure 4.

(2) When $\mu>A /\left(I_{2} \beta+I_{1} \varepsilon+\alpha_{2} c_{1}-I_{1} \varepsilon \gamma\right),\left\{\begin{array}{l}F(1)=0 \\ F^{\prime}(1)<0\end{array}\right.$. So, $\eta=1$ is the evolutionary stable strategy.

If the government supervision probability $\mu>A$ / $\left(I_{2} \beta+I_{1} \varepsilon+\alpha_{2} c_{1}-I_{1} \varepsilon \gamma\right)$, technology adoption $(\eta=1)$ is the stable strategy. That is, in the initial stage, if $\mu>\mu^{*}$, even the farmers do not adopt IoT vegetable disease warning technology, after continuous observation and learning, they will eventually adopt the technology. The evolution phase diagram is shown in Figure 5.

In summary, if the government supervision probability is equal to $\mu^{*}$, the adoption probability of the farmer is equal to any value in $[0,1]$. When

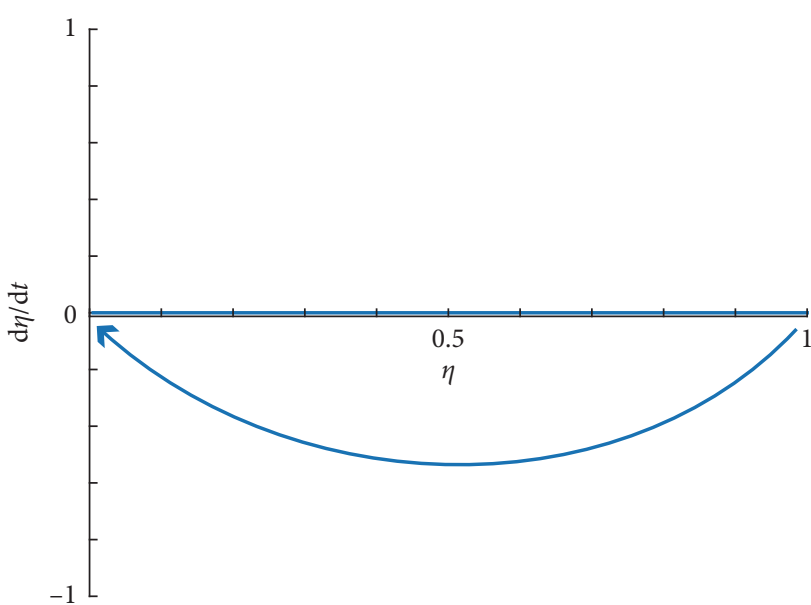

FIgURE 4: The evolution phase diagram of $\mu<\mu^{*}$.

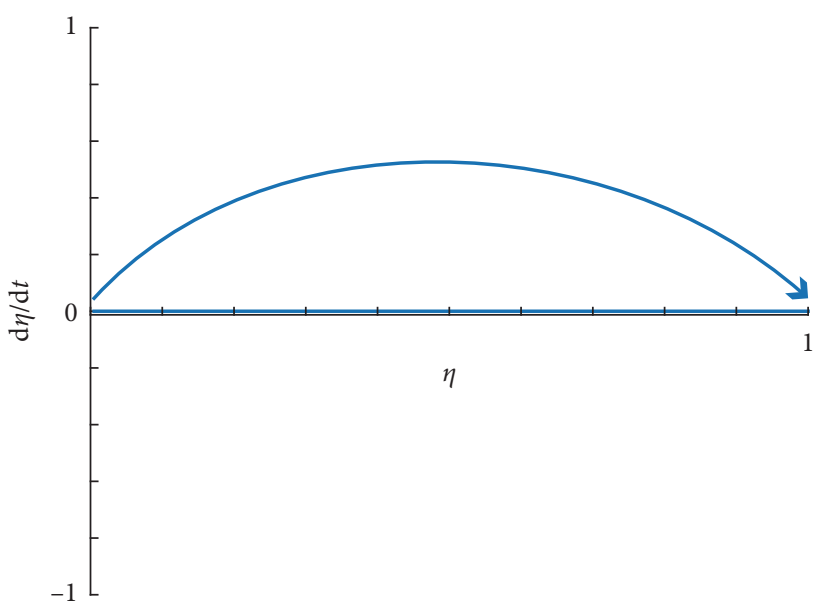

FIgURE 5: The evolution phase diagram of $\mu>\mu^{*}$.

the probability of government supervision is less than $\mu^{*}$, farmers will gradually refuse to adopt. When the government supervision probability is greater than $\mu^{*}$, after a series of strategic adjustments, farmers would eventually choose to adopt the technology of intelligent disease warning technology. All possibilities can be expressed by the following equation:

$$
n=\left\{\begin{aligned}
1 \quad & \text { if } \mu>\mu^{*}, \\
{[0,1] } & \text { if } \mu=\mu^{*}, \\
0 \quad & \text { if } \mu<\mu^{*}, \\
\mu^{*} & =\frac{A}{I_{2} \beta+I_{1} \varepsilon+\alpha_{2} c_{1}-I_{1} \varepsilon \gamma}, \\
A & =c_{1}-c_{2}-c_{N}-v_{F}-I_{1} \alpha_{1}+I_{2} \alpha_{1}+I_{1} \varepsilon-I_{2} \varepsilon .
\end{aligned}\right.
$$


3.4. The Expected Function of Local Government. The government's revenue of supervision is

$$
\begin{aligned}
E_{\text {supervision }}^{\prime}= & \eta\left[(1-\sigma) R_{s}-c_{3}+r \varepsilon I+v_{G}\right] \\
& +(1-\eta)\left(\varepsilon I_{2}+\beta I_{2}-c_{3}\right) .
\end{aligned}
$$

The government's revenue of nonsupervision is

$$
E_{\text {non-supervision }}^{\prime}=\eta\left(R_{s}+\varepsilon I_{1}+v_{G}\right)+(1-\eta)\left(\varepsilon I_{2}-v_{G}\right) \text {. }
$$

The government's revenue is

$$
E_{\text {government }}^{\prime}=\mu E_{\text {supervision }}^{\prime}+(1-\mu) E_{\text {non-supervision }}{ }^{\prime} \text {. }
$$

The replication dynamic equation of government supervision is

$$
\begin{aligned}
F(\mu)= & \frac{\mathrm{d} \mu}{\mathrm{d} t} \\
= & \mu\left(E_{\text {supervision }}^{\prime}-E_{\text {government }}^{\prime}\right) \\
= & \mu(\mu-1)\left(c_{3}-v_{G}-I_{2} \beta+\eta v_{G}+I_{2} \beta \eta\right. \\
& \left.+I_{1} \varepsilon \eta+\sigma \eta R_{s}-I_{1} \varepsilon \eta \gamma\right) .
\end{aligned}
$$

3.4.1. The Stable State of the System. Let $F(\mu)=0$; get $\mu^{*}=$ 0,1 or $\eta^{*}=\left(v_{G}-c_{3}+I_{2} \beta\right) /\left(v_{G}+I_{2} \beta+I_{1} \varepsilon+\sigma R_{s}-I_{1} \varepsilon \gamma\right)$.

That means when the farmer's adoption probability $\eta=\eta^{*}=\left(v_{G}-c_{3}+I_{2} \beta\right) /\left(v_{G}+I_{2} \beta+I_{1} \varepsilon+\sigma R_{s}-I_{1} \varepsilon \gamma\right)$, any value of $\mu$ in $[0,1]$ can make $F(\mu)=0$. So, when $\eta=\eta^{*}$, the government's supervision and nonsupervision strategies could not change the adoption level of farmer. The evolution phase diagram is shown in Figure 6.

3.4.2. Summary of Evolutionary Paths. The stability strategy of government evolutionary game needs to satisfy the following equation:

$$
\left\{\begin{array}{l}
F(\mu)=0, \\
F^{\prime}(\mu)=\frac{\mathrm{d}[F(\mu)]}{\mathrm{d} \mu}<0 .
\end{array}\right.
$$

where

$$
\begin{aligned}
F^{\prime}(\mu)= & \frac{\mathrm{d}[F(\mu)]}{\mathrm{d} \mu} \\
= & (1-2 \mu)\left[\left(v_{G}-c_{3}+I_{2} \beta\right)\right. \\
& \left.-\eta\left(v_{G}+I_{2} \beta+I_{1} \varepsilon+\sigma R_{s}-I_{1} \varepsilon \gamma\right)\right] .
\end{aligned}
$$

Next, the different situations of $\left(v_{G}-c_{3}+I_{2} \beta\right)-\eta\left(v_{G}+\right.$ $\left.I_{2} \beta+I_{1} \varepsilon+\sigma R_{s}-I_{1} \varepsilon \gamma\right)$ will be discussed:

(1) When farmer adoption probability $\eta>\left(v_{G}-c_{3}+\right.$ $\left.I_{2} \beta\right) /\left(v_{G}+I_{2} \beta+I_{1} \varepsilon+\sigma R_{s}-I_{1} \varepsilon \gamma\right),\left\{\begin{array}{l}F(0)=0 \\ F^{\prime}(0)<0\end{array}\right.$. So, government supervision probability $\mu=0$ is stable evolutionary strategy. That means when farmer adoption probability $\eta>\eta^{*}$, the local government gives up supervision, as shown in Figure 7.

(2) When farmer's adoption probability $\eta<\left(v_{G}-c_{3}+\right.$ $\left.I_{2} \beta\right) /\left(v_{G}+I_{2} \beta+I_{1} \varepsilon+\sigma R_{s}-I_{1} \varepsilon \gamma\right), \quad\left\{\begin{array}{l}F(1)=0 \\ F^{\prime}(1)<0\end{array}\right.$, government supervision probability $\mu=1$ is the evolutionary stable strategy. The evolution phase diagram is shown in Figure 8.

In summary, when the adoption level of farmers is equal to $\eta^{*}$, the government will not change the original decision; when the adoption level of farmers is greater than $\eta^{*}$, the government will abandon supervision; when the adoption level of farmers is less than $\eta^{*}$, the government will implement supervision strategy. Equation (14) gives the description.

$$
\mu=\left\{\begin{aligned}
0 \quad & \text { if } \eta>\eta^{*}, \\
{[0,1] } & \text { if } \eta=\eta^{*}, \\
1 \quad & \text { if } \eta<\eta^{*}, \\
& \eta^{*}=\frac{v_{G}-c_{3}+I_{2} \beta}{v_{G}+I_{2} \beta+I_{1} \varepsilon+\sigma R_{s}-I_{1} \varepsilon \gamma} .
\end{aligned}\right.
$$

So, in initial stage of application, the government needs to continue increasing supervision and encouragement in order to promote the continued adoption of farmers. Otherwise, the previous achievements will disappear and farmers will once again turn to traditional chemical techniques to resist vegetable diseases. When the adoption level of farmers reaches a certain level $\eta>\eta^{*}$, the government can try to relax or stop supervision and form a sustainable cycle of technology adoption for saving social resources, as shown in Figure 9.

How to achieve a breakthrough from the initial stage to the sustainable development stage? This problem will be analyzed in Section 4.

\section{The System Evolution}

Based on analysis in Section 3, the evolution state diagram of the system is obtained.

In Figure 10, the evolution space is composed of $\eta$ and $\mu\{(\eta, \mu): 0 \leq \eta \leq 1,0 \leq \mu \leq 1\}$, and there are five equilibrium points: $O(0,0), A(1,0), B(0,1), C(1,1)$, and $D\left(\eta^{*}, \mu^{*}\right)$.

$$
\begin{aligned}
& \eta^{*}=\frac{v_{G}-c_{3}+I_{2} \beta}{v_{G}+I_{2} \beta+I_{1} \varepsilon+\sigma R_{s}-I_{1} \varepsilon \gamma}, \\
& \mu^{*}=\frac{A}{I_{2} \beta+I_{1} \varepsilon+\alpha_{2} c_{1}-I_{1} \varepsilon \gamma} .
\end{aligned}
$$

(1) Let $S_{B D C}=S_{1}, S_{A D O}=S_{2}$; areas of $S_{1}$ and $S_{2}$ determine the direction of system evolution. When $S_{1}>S_{2}$, the evolution probability to $C$ is greater than 


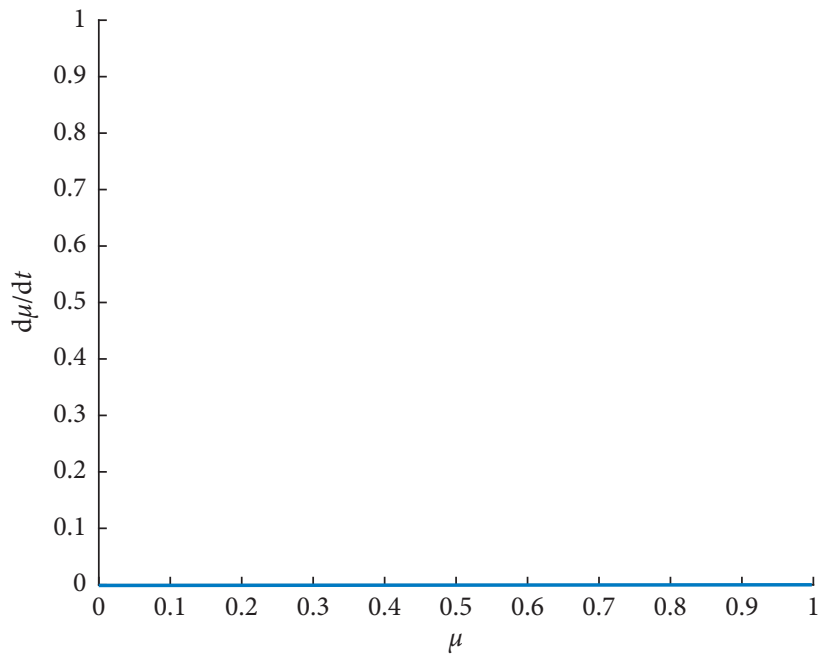

FIgURE 6: The evolution phase diagram when $\eta=\eta^{*}$.

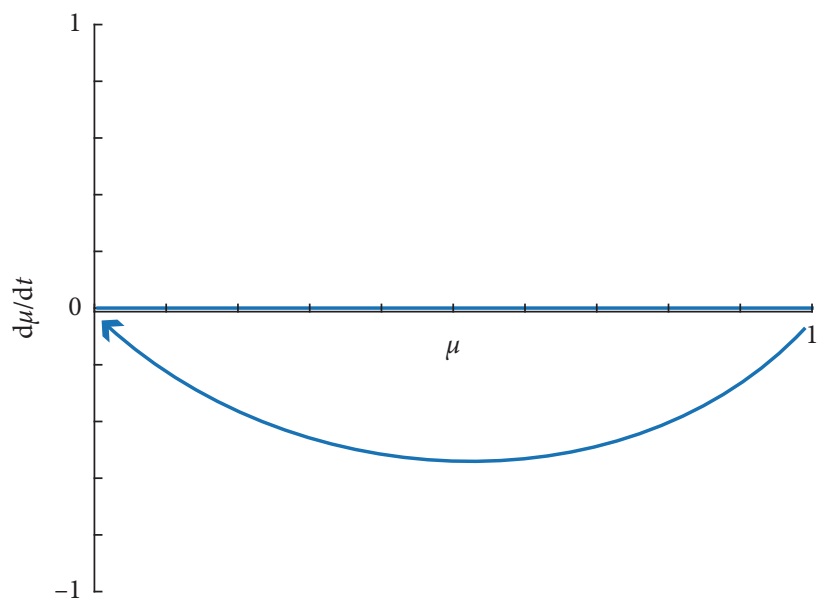

FIgURE 7: The evolution phase diagram when $\eta>\eta^{*}$.

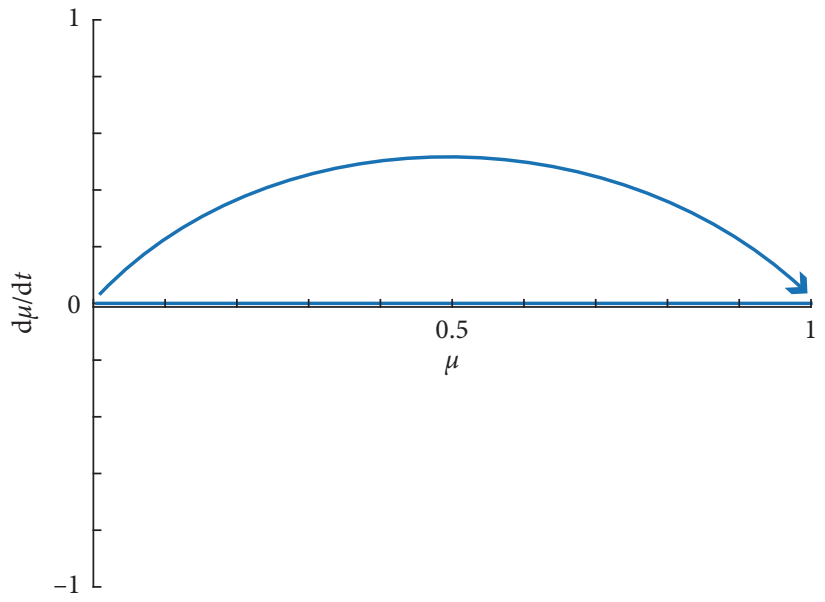

FIgURE 8: The evolution phase diagram of $\eta<\eta^{*}$. 


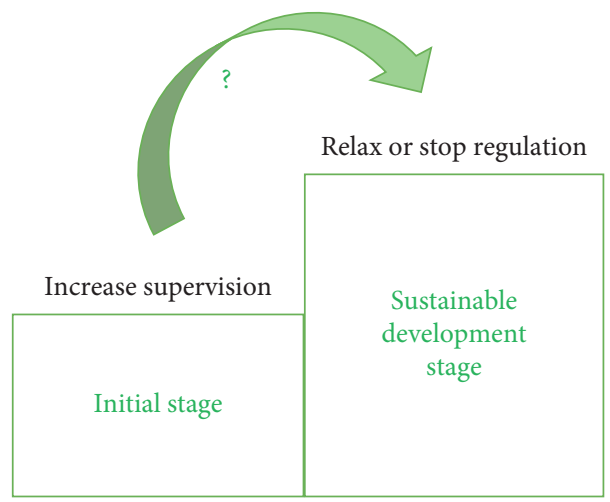

FIgURE 9: Initial promotion and sustainable adoption.

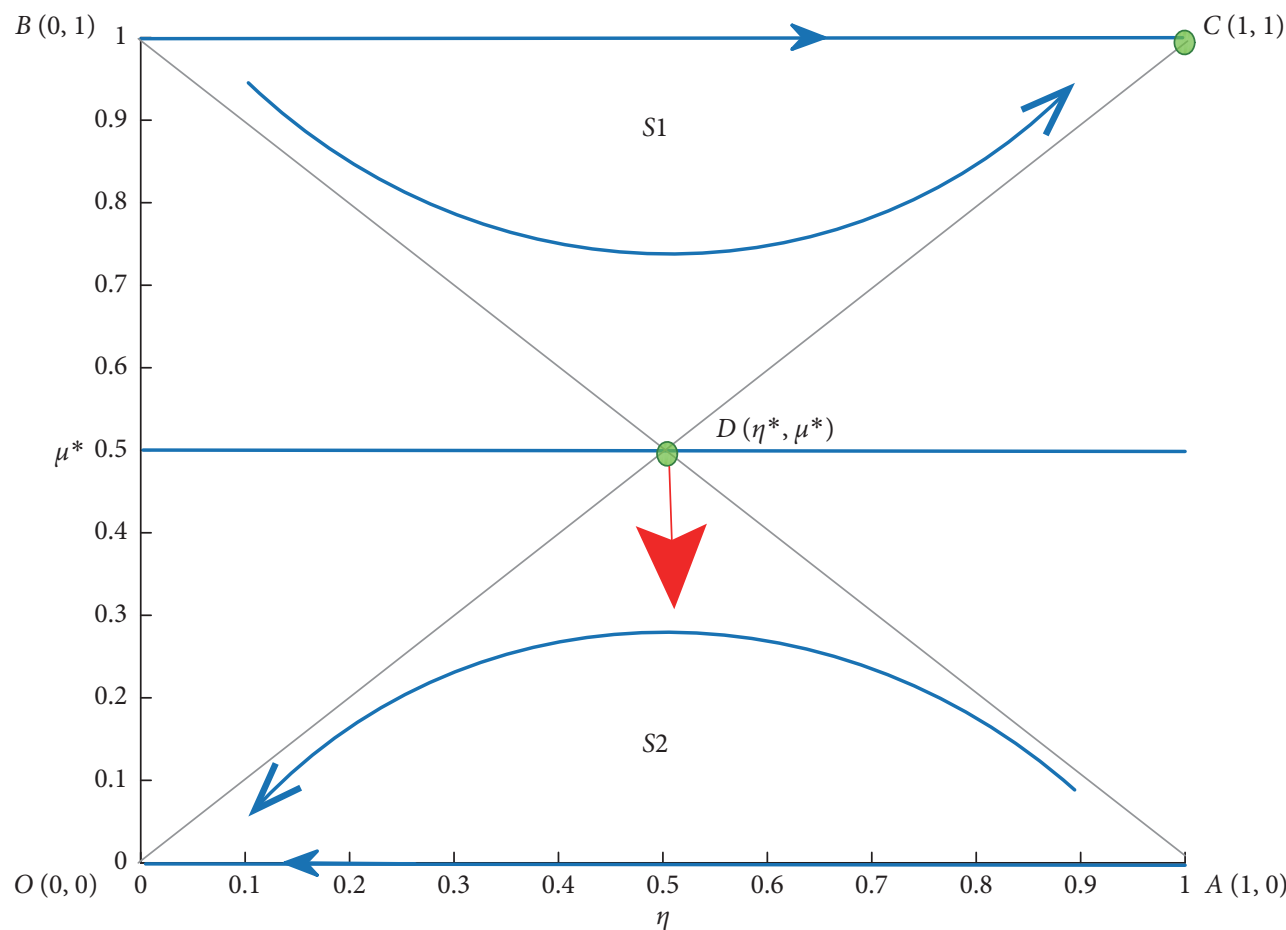

Figure 10: The evolution state of the system.

the probability to $O$; when $S_{2}>S_{1}$, evolution probability to $O$ is greater than the probability to $C$.

Let $S_{1}>S_{2}$ (the direction of red arrow in Figure 9):

$$
\begin{gathered}
\frac{c_{2}-c_{1}+c_{N}+v_{f}+I_{1} \alpha_{1}-I_{2} \alpha_{1}-I_{1} \varepsilon+I_{2} \varepsilon}{2\left(I_{2} \beta+I_{1} \varepsilon+\alpha_{2} c_{1}+I_{1} \varepsilon \gamma\right)}+\frac{1}{2} \\
>\frac{-\left(c_{2}-c_{1}+c_{N}+v_{f}+I_{1} \alpha_{1}-I_{2} \alpha_{1}-I_{1} \varepsilon+I_{2} \varepsilon\right)}{2\left(I_{2} \beta+I_{1} \varepsilon+\alpha_{2} c_{1}+I_{1} \varepsilon \gamma\right)} .
\end{gathered}
$$

That is,

$$
\begin{aligned}
& \frac{c_{2}-c_{1}+c_{N}+v_{f}+I_{1} \alpha_{1}-I_{2} \alpha_{1}-I_{1} \varepsilon+I_{2} \varepsilon}{I_{2} \beta+I_{1} \varepsilon+\alpha_{2} c_{1}+I_{1} \varepsilon \gamma} \\
& +\frac{c_{2}-c_{1}+c_{N}+v_{f}+I_{1} \alpha_{1}-I_{2} \alpha_{1}-I_{1} \varepsilon+I_{2} \varepsilon}{I_{2} \beta+I_{1} \varepsilon+\alpha_{2} c_{1}+I_{1} \varepsilon \gamma}<-\frac{1}{2}
\end{aligned}
$$

The model evolves to $C$ ffarmer adoption; government regulation\}.

(2) In Figure 11, let $S_{C D A}=S_{3}, S_{B D O}=S_{4}$; when $S_{3}>S_{4}$, the probability of evolving to $A$ is greater than the probability of evolving to $B$ and vice versa. 


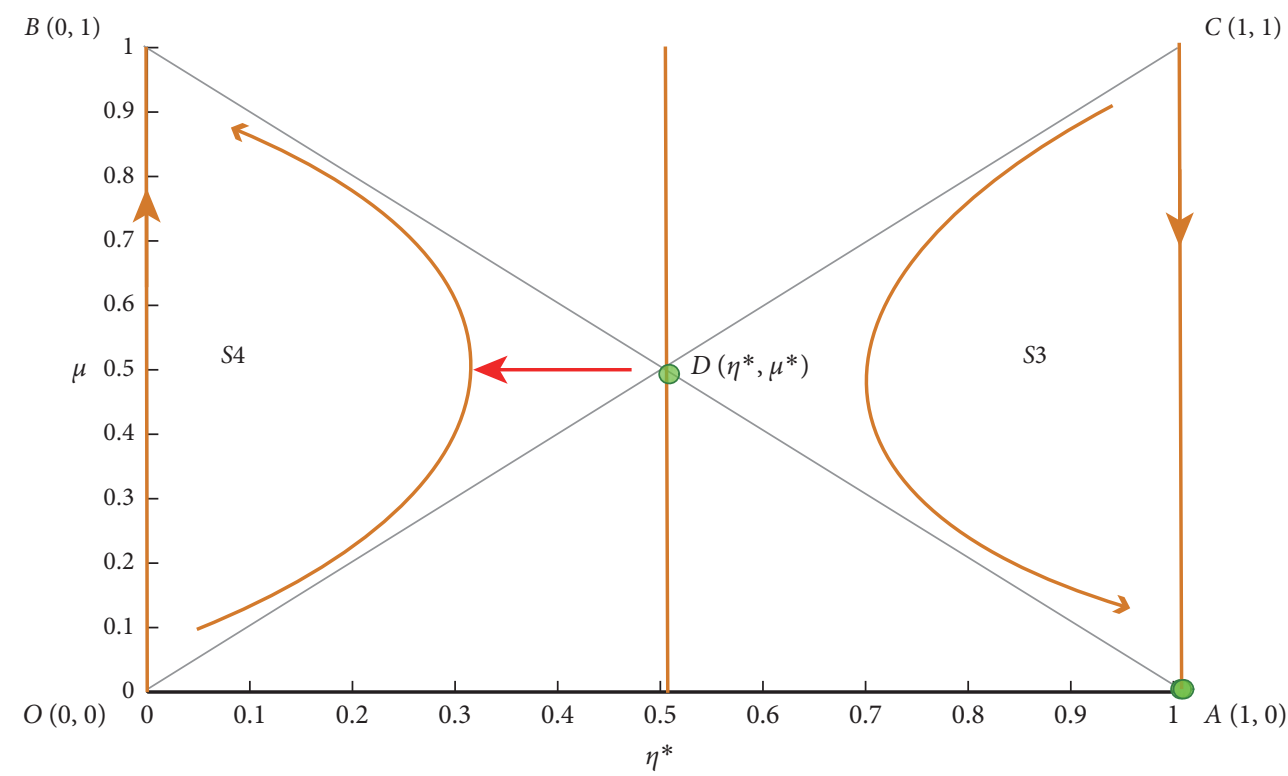

Figure 11: The evolution state of the system.

Let $S_{3}>S_{4}$ (the direction of red arrow in Figure 10); get

$$
\begin{gathered}
\frac{1-\left(v_{g}-c_{3}+I_{2} \beta\right)}{2\left(v_{g}+I_{2} \beta+I_{1} \varepsilon+b R_{s}-I_{1} \varepsilon \gamma\right)} \\
>\frac{v_{g}-c_{3}+I_{2} \beta}{2\left(v_{g}+I_{2} \beta+I_{1} \varepsilon+b R_{s}-I_{1} \varepsilon \gamma\right)} .
\end{gathered}
$$

Namely,

$$
v_{g}-c_{3}+I_{2} \beta<\frac{1}{2}
$$

The model evolves to $A$ ffarmer adoption; government nonregulation\}.

(3) The evolutionary features of the system:

Figure 12 is the evolution diagram of the system; $D$, $C$, and $A$ are three important points.

Theorem 1 (see the appendix for proof). $D\left(\eta^{*}, \mu^{*}\right)$ is the saddle point of the evolutionary model.

Theorem 2 (see the appendix for proof). When $\left\{\left(c_{2}-c_{1}+\right.\right.$ $\left.c_{N}+v_{f}+I_{1} \alpha_{1}-I_{2} \alpha_{1}-I_{1} \varepsilon+I_{2} \varepsilon\right) /\left(I_{2} \beta+I_{1} \varepsilon+\alpha_{2} c_{1}-I_{1} \varepsilon \gamma\right)$ $<-(1 / 2) v_{g}-c_{3}+I_{2} \beta<(1 / 2)$, with increasing cost subsidy from the government, farmers'negative feedback of refusing technology, positive feedback of the government, and chemical agriculture cost, the system evolves to $C(1,1)$ : ffarmer adoption; government regulation\}.

Theorem 3. With the increase of cost subsidy from the government, the system evolves to $C(1,1)$ : \{farmer adoption; government regulation\}.

Theorem 4. With the increase of farmers' negative feedback of refusing technology, the system evolves to $C(1,1)$.
Theorem 5. With the increase of positive feedback of the government, the system evolves toward $C(1,1)$.

Theorem 6. With the increase of chemical agriculture cost, such as pesticides and fertilizers, the system evolves toward $C$ $(1,1)$.

In summary, increasing cost subsidy, farmers' negative feedback, government's positive feedback, and chemical agriculture cost will make the system evolve to point C: ffarmer adoption; government regulation\}. However, strategy $C$ relies heavily on the government, and it is not a sustainable way of technology diffusion.

(4) Bottleneck of sustainable development and countermeasures:

Theorem 7 (see the appendix for proof). When $I_{2} \beta+I_{1} \varepsilon$ $-I_{1} \varepsilon \gamma+a_{2} c_{2}+a_{2} c_{N}+a_{2} v_{f}+I_{1} a_{1} a_{2}-I_{2} a_{1} a_{2}-I_{1} a_{2} \varepsilon+I_{2} a_{2}$ $\varepsilon>0$, with decreasing the cost of IoT equipment $c_{1}$, the system evolves toward the direction of $A(1,0)$. That is, farmers adopt and the government does not supervise.

In China, most agricultural sensors, agricultural wireless sensor networks, and other agricultural IoT equipment rely on imports; prices are high and farmers cannot afford them. The high cost of agricultural IoT is the bottleneck for sustainable adoption. However, in industry, IoT devices have been deeply developed and applied. According to Moore's or post-Moore's law [31, 32], the price of IoT equipment's unit function gradually decreases with the development of technology, as shown in Figure 13.

The devices' costs of agricultural IoT and industrial IoT show a clear gap [9]. To get rid of this backward state in agriculture, one of the important ways is to reduce the cost gap, namely, reduce the cost of $c_{1}$. Efforts can be made in following aspects in China. 


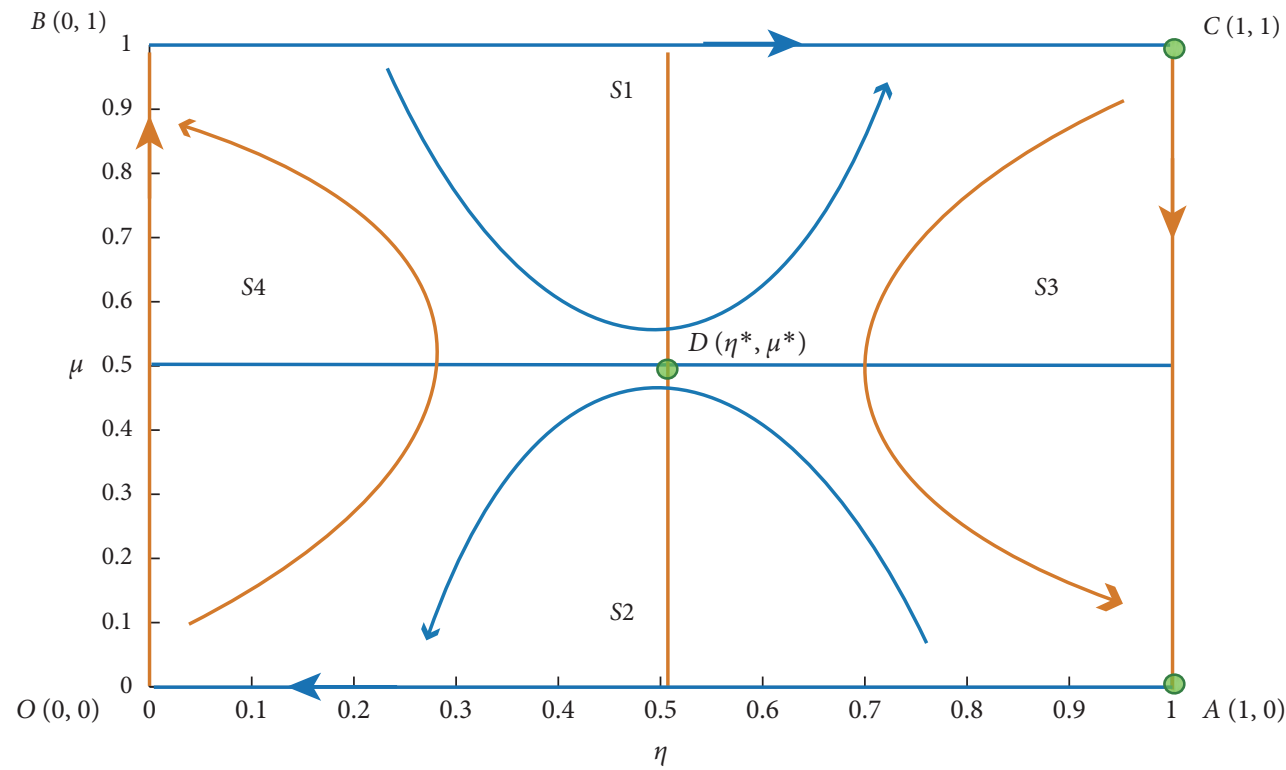

Figure 12: The evolution diagram of the system.

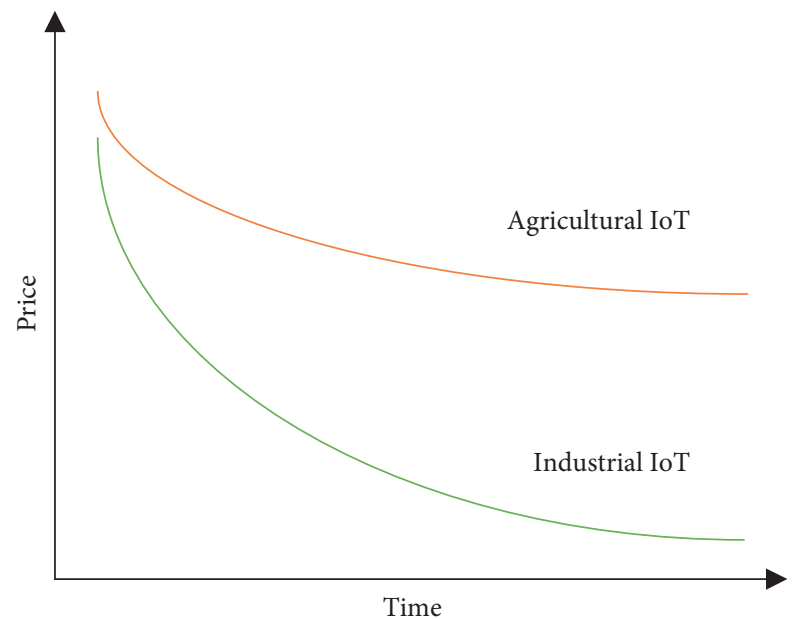

Figure 13: The price trends of IoT devices in industry and agriculture.

For reducing the cost of agricultural IoT equipment, the current situation of dependence on imports should be changed and IoT R\&D on agriculture should be encouraged.

Small-scale production should be replaced with largescale agricultural production, the quality and value of agricultural products should be improved, and highquality green agriculture should be developed for increasing farmers' profits.

In-depth integration between IoT technology and agriculture should be encouraged.

\section{Dynamic Evolution of Adoption Level in Competitive Market}

In Section 4, the relationship between government promotion and farmer adoption in early application stage is analyzed. However, in China, the application level of agricultural IoT technology is uneven and heavily dependent on government subsidy, which is a noncommercially unsustainable development path in the long run. Market competitiveness is an important criterion for testing the survivability of new technologies. And capacity sharing is an effective way to achieve complementary and coordinated development. In this section, for sustainable development, we will study the dynamic fluctuation characteristics of the adoption level in the competitive market under capacity sharing.

5.1. Assumptions and Notations. Assume that there are two groups of agricultural companies: Group 1 and Group 2; firms in Group 1 adopt IoT disease warning technology, and firms in Group 2 reject IoT technology and use chemical farming technology. Due to the use of agricultural IoT equipment, Group 1 has a strong production capacity and can provide excess capacity to Group 2 . We suppose that the set of choices is a convex set and each group's profit is concave in their own strategy; this guarantees the existence of Nash equilibrium [33, 34].

(1) $i$ represents strategy space of technology choice, $i \in\{1,2\} .1$ means choice; 2 means rejection.

(2) The outputs of two groups are

$$
y_{i}=a_{i}-o_{i} p_{i}+\lambda_{i} p_{i}+r_{i} v \rho, \quad(i=1,2) .
$$

$a_{i}$ is potential demand base which is not related to price [33]. $o_{i}$ and $\lambda_{i}$ are the sensitivity coefficients of price on demand, $\rho(\rho \geq 0)$ indicates the potential excess capacity of firm 1 that can be shared with firm 2. $r_{i}$ represents the sensitivity coefficient of demand to capacity sharing, and $o_{i}>\lambda_{i}>r_{i}$. Since the production processes of the two players are not exactly 
matched, the matching capacity coefficient $0 \leq v \leq 1$. $v=0$ means that the excess capacity of enterprise 1 cannot produce product 2 , and $\nu=1$ means that the excess capacity of agricultural enterprise 1 can be used to produce agricultural product 2. For the convenience of analysis, we make $a_{1}=a_{2}=a, o_{1}=$ $o_{2}=o, \lambda_{1}=\lambda_{2}=\lambda, r_{1}=r_{2}=r$.

(3) The cost:

Internet of Things technology can improve green degree of agricultural products [35], so the cost of products is as follows:

$$
J_{1}=j_{1} y_{1}+\frac{1}{2} n v^{2}+\frac{1}{2} \kappa L^{2}-\tau L y_{1}
$$

where $j_{1}$ is the marginal cost, $(1 / 2) n v^{2}$ is the match cost, $(1 / 2) \kappa L^{2}$ is the hardware and software platform cost, $L$ is the green degree of output, and $\tau$ is the parameter of government subsidy.

$$
J_{2}=\left(j_{2}+\kappa\right)\left(y_{2}-v \rho\right)+\left(j_{1}+p_{\text {match }}\right) v \rho
$$

where $\kappa y_{2}$ is the chemical cost, $\left(j_{1}+p_{\text {match }}\right) v \rho$ is the OEM (original equipment manufacturer) cost that is paid by enterprise 2 , and $p_{\text {match }}$ is the shared capacity costs.

(5) The profits of the two enterprises are

$$
\begin{aligned}
& \prod_{1}=\left(a_{1}-o_{1} p_{1}+\lambda_{1} p_{2}+r v \rho\right) p_{1}-\left[j_{1}\left(a_{1}-o_{1} p_{1}+\lambda_{1} p_{2}+r v \rho\right)+\frac{1}{2} n v^{2}+\frac{1}{2} \kappa L^{2}-\tau L\left(a_{1}-o_{1} p_{1}+\lambda_{1} p_{2}+r v \rho\right)\right] \\
& \prod_{2}=\left(a_{2}-o_{2} p_{2}+\lambda_{2} p_{1}+r v \rho\right) p_{2}-\left[\left(j_{2}+k\right)\left[\left(a_{2}-o_{2} p_{2}+\lambda_{2} p_{1}+r v \rho\right)-v \rho\right]+\left(j_{1}+p_{\text {match }}\right) v \rho\right] .
\end{aligned}
$$

5.2. The Dynamic Technology adoption Model in Competitive Market. The dynamic model of technology adoption is

$$
p_{i}(t+1)=P\left[p_{1}(t), p_{2}(t), w(t)\right], \quad i=1,2,
$$

where $w(t)$ is the adoption ratio of period $t$ among players and follows asynchronous update mechanism which is based on the exponential replicator model [35]. The model is described by the following equation:

$$
\left\{\begin{array}{l}
p_{1}(t+1)=p_{1}(t)+\psi p_{1}(t) \frac{\mathrm{d} \prod_{1}(t)}{\mathrm{d} p_{1}(t)} \\
p_{2}(t+1)=p_{2}(t)+\xi p_{2}(t) \frac{\mathrm{d} \prod_{2}(t)}{\mathrm{d} p_{2}(t)} \\
w(t+1)=\frac{w(t) e^{\delta \% \prod_{1}(t)}}{w(t) e^{\delta \%} \prod_{a}(t)}+[1-w(t)] e^{\delta \% \prod_{2}(t)}
\end{array}\right.
$$

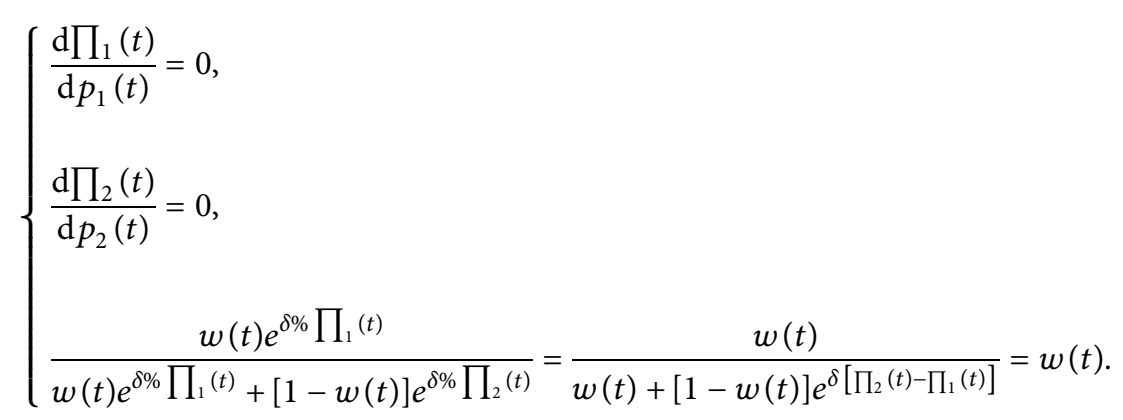

Two groups of players use limited rational expectations and aim at maximizing profits, that is, the enterprise adjusts current price based on the profit obtained from previous period. When the previous profit is positive (or negative), the price will be increased (or decreased) in the current period. That is,

$$
p_{i}(t+1)=p_{i}(t)+e p_{i}(t) \frac{\mathrm{d} \prod_{i}(t)}{\mathrm{d} p_{i}(t)}, \quad i=1,2 ; e=\psi, \xi
$$

In (26), $\delta$ is the coefficient for the intensity of choice. If $\delta=0, w(t+1)=w(t)$; if $\delta \longrightarrow \infty$, agricultural enterprises immediately adopt new technology which brings efficient production. $\Pi_{1}(t)$ and $\prod_{2}(t)$ are expressed by equations (23) and (24). $\psi$ and $\xi$ are price adjustment speeds that are nonzero.

By solving equation (28), the equilibrium point of the system is obtained:

The Nash equilibrium prices are

\footnotetext{
The Nash equilibrium prices are
} 


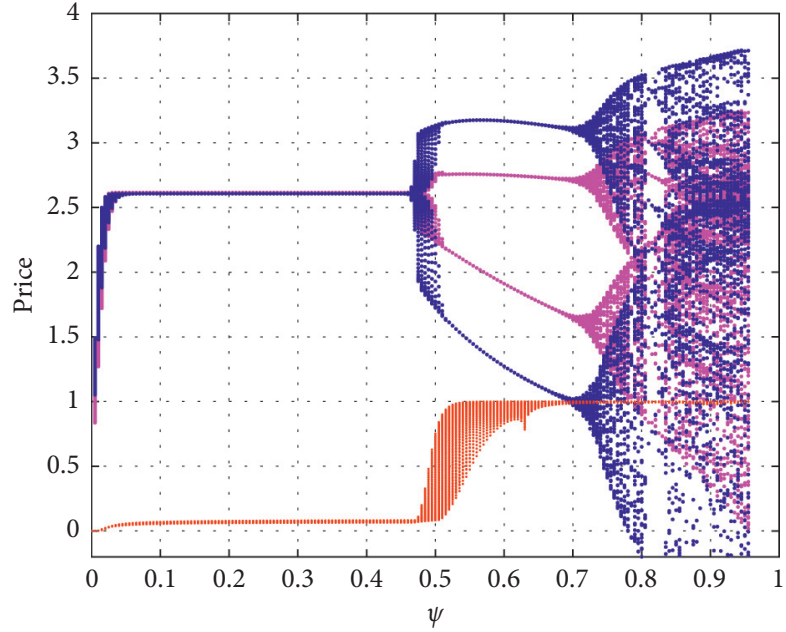

(a)

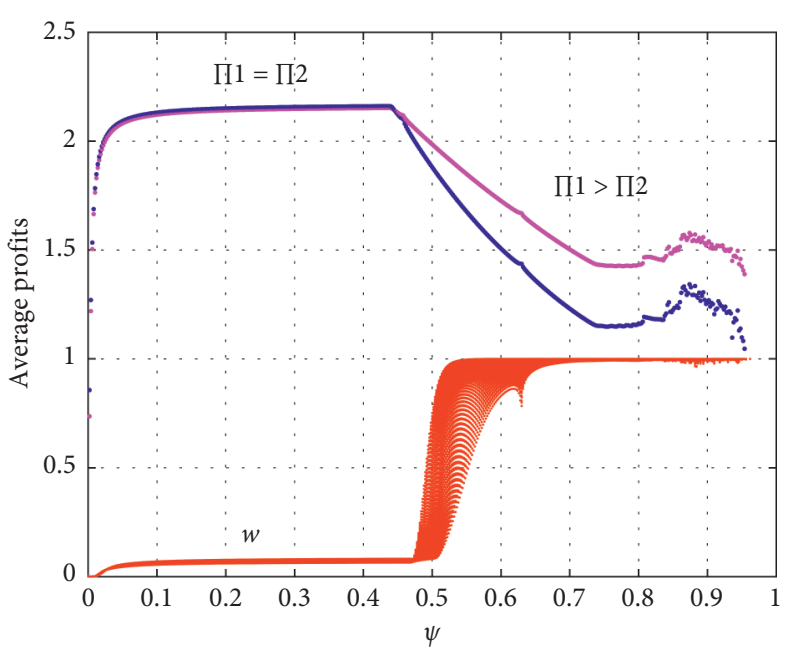

(b)

Figure 14: $\prod_{1}=\prod_{2}$ in Nash equilibrium stage.

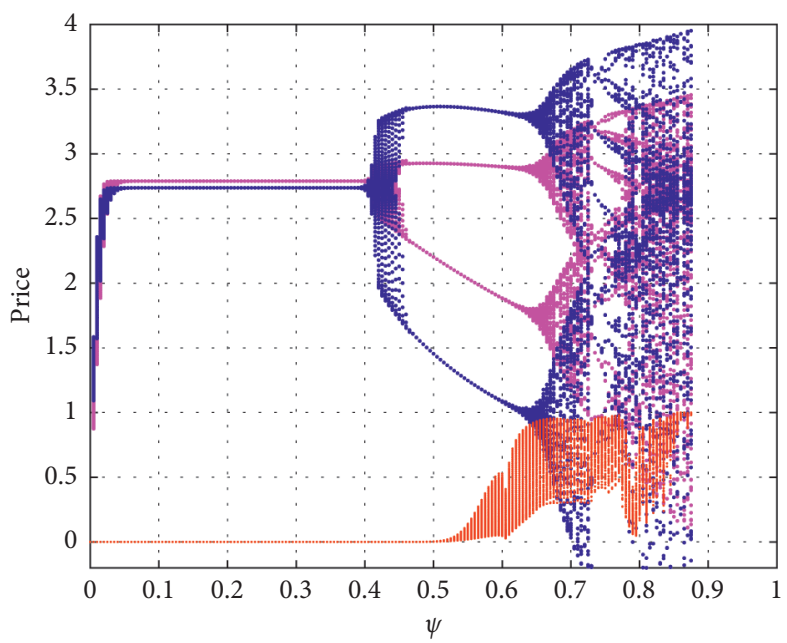

(a)

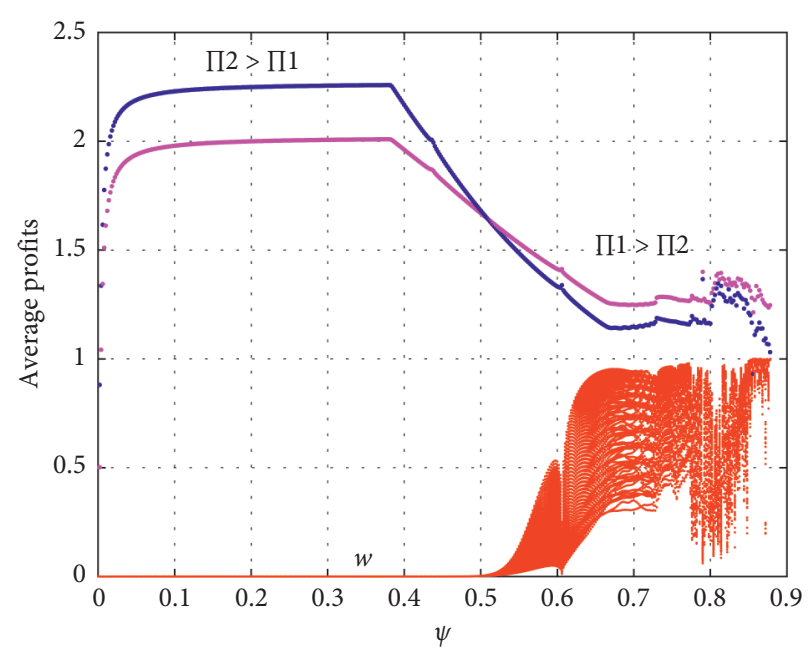

(b)

Figure 15: $\prod_{2}>\prod_{1}$ in equilibrium stage.

$p_{1}^{*}=\frac{2 a o+a \lambda+2 \alpha^{2} j_{1}+o \lambda j_{2}+o \lambda \kappa-2 L o^{2} \tau+2 o \rho r_{1} v+\lambda \rho r_{1} v}{4 o^{2}-\lambda^{2}}$ $p_{2}^{*}=\frac{2 a o+a \lambda+2 \alpha^{2} j_{2}+2 o^{2} \kappa+o \lambda j_{1}+2 o \rho r_{1} v+\lambda \rho r_{1} v-L o \lambda \tau}{4 o^{2}-\lambda^{2}}$

The adoption ratio is $w(t)=1$ or $w(t)=0$.

\subsection{Characteristics of the Competitive Evolution}

Theorem 8 (see the appendix for proof). When the longrun average profit of adopter equals to the long-run average profit of rejector, the adoption ratio can be any value between 0 and 1 . When the long-run average profit of adopter is greater than (less than) the long-run average profit of rejector, the market adoption ratio tends to $100 \%$ (0).
Theorem 9. If $\prod_{1}=\prod_{2}$, the equilibrium point of the system is $P^{*}\left[p_{1}^{*}, p_{2}^{*}, w\right](w \in[0,1])$ which is a stable point. At this time, farmers have no incentive to change their current technology selection strategy.

Theorem 10. If $\prod_{1}>\prod_{2},\left(p_{1}^{*}, p_{2}^{*}, 1\right)$ is the stable equilibrium point of the model. At this time, vegetable early warning technology can bring more profits for farmers. After many observations and comparisons, farmers finally adopt the technology, and the adoption ratio in market evolves to $100 \%$.

Theorem 11. If $\prod_{1}<\prod_{2},\left(p_{1}^{*}, p_{2}^{*}, 0\right)$ is the stable equilibrium point of the model. Because the adoption of agricultural Internet of Things technology will reduce profits, farmers gradually give up, and the adoption ratio gradually tends to 0 . 


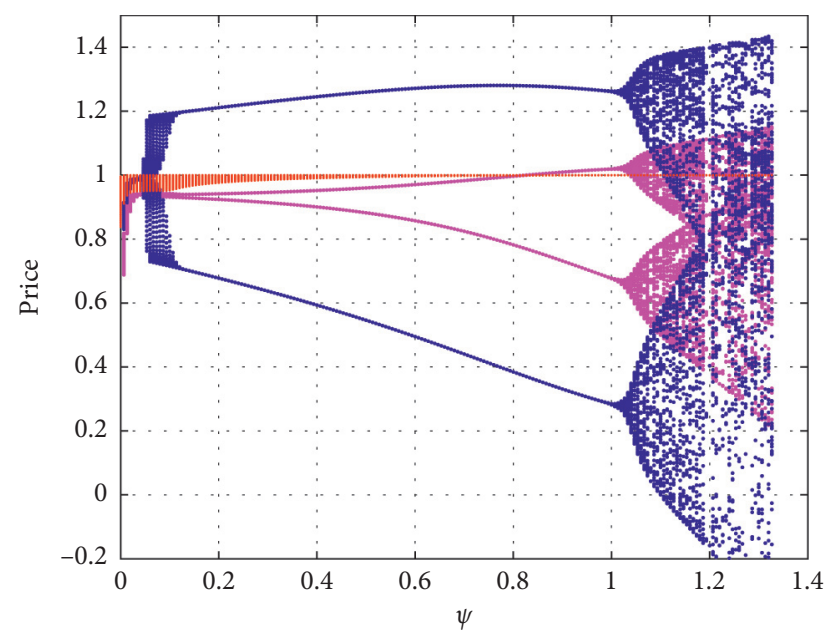

(a)

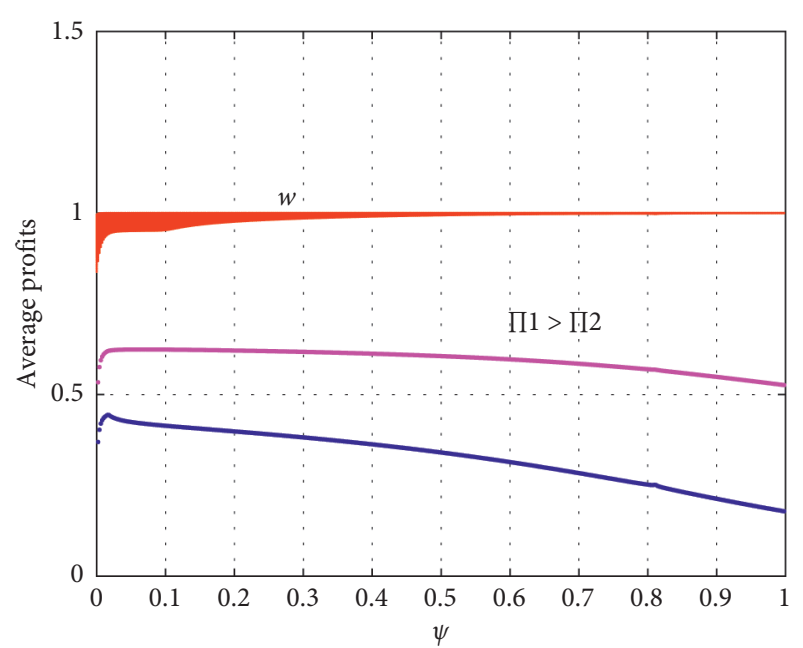

(b)

Figure 16: $\prod_{1}>\prod_{2}$ in equilibrium stage.

5.4. Numerical Simulation: Adoption Equilibrium and Dynamic Transition. In this section, Theorem 8 is verified by numerical simulation.

The market is divided into two stages: the Nash equilibrium stage and the complex fluctuation stage (including periodic and chaotic fluctuations). In the complex fluctuation stage, the long-term average profit is used to study the change of adoption ratio [36] as described in the following equation::

$$
\prod_{i=1,2}=\frac{1}{T} \sum_{t=1}^{t=T} \prod_{i}\left(p_{1_{t}}, p_{2_{t}}\right), \quad i=1,2 ; T=10^{3} .
$$

(1) $w \in[0,1]\left(\right.$ when $\left.\prod_{1}=\prod_{2}\right) \Rightarrow w=1\left(\right.$ when $\left.\prod_{1}>\prod_{2}\right)$ Figures 14(a) and 14(b) are dynamic evolutions of price and profit with changing $\psi$. Red color indicates adoption ratio. The adoption ratio is $9.8 \%$ in the Nash equilibrium stage, and in this time, $\Pi_{1}=\Pi_{2}$. When $\varphi>0.475, \prod_{1}>\prod_{2}$, the adoption ratio gradually evolves to $100 \%$ in Figure 14(b).

(2) $w=0\left(\prod_{1}<\prod_{2}\right) \Rightarrow w=1\left(\prod_{1}>\prod_{2}\right)$

In Figures 15(a) and 15(b), in the Nash equilibrium phase, $\prod_{2}>\prod_{1}$, the adoption ratio $w=0$. When $\varphi>0.49$, the adoption ratio $w$ gradually evolves to 1 .

(3) $w=1\left(\right.$ when $\left.\prod_{1}>\prod_{2}\right)$

Figure 16(b) shows the long-run average profit of Figure 16(a). For $\prod_{1}>\prod_{2}$, the market adoption rate $w=100 \%$. Above simulations verified Theorem 8 .

In the competitive market, the long-term average profit of player determines the evolution direction of IoT technology adoption ratio. When the average profit of technology adopter is greater than the average profit of rejector, the adoption rate evolves to 1 . Therefore, reducing the cost of technology, improving technology use efficiency, and increasing profit are effective ways for sustainable development of the agricultural Internet of Things.

\section{Conclusion}

The article explores the development characteristics of agricultural IoT industry in China from two perspectives: government support in initial stage and sustainable development mechanism in the long run. For studying the evolutionary characteristics of the relationship between government and farmers, the research builds an evolutionary game model between government support and farmer adoption and finds that increasing cost subsidy given by the government, increasing negative feedback of farmers refusing technology, increasing positive feedback of the government, and increasing chemical agriculture cost can help the system evolve to the strategy set: ffarmer adoption; government support\}. Reducing the cost of agricultural IoT equipment can make the system turn to (farmer adoption; government nonregulation) which is a more optimized and cost-saving strategy combination. Relying on government support is not a healthy development way in the long run. A sustainable development mechanism that is suitable for market competition should be established. So, based on dynamic competition and technology selection theory, a dynamic evolution model about farmers' adoption ratio in a competitive market is constructed. It is found that due to intensified competition, the market shows cyclic and chaotic fluctuations. In this complex market, the adoption status is determined by the long-run average profit. When the longrun average profit of adopter is greater than (less than) the long-run average profit of rejector, the market adoption ratio tends to $100 \%(0)$. When they are equal, the adoption ratio can be any value between 0 and 1 .

Through the above analysis, the summary of the agricultural IoT technology promotion plan is as follows. (1) In the early stage of application, continuing to increase supervision, subsidy, and encouragement can prevent the loss of early promotion results. (2) In the sustainable development stage, when farmers' adoption ratio reaches a certain level, the government can try to relax or stop supervision. 
This approach can save promotion costs. (3) Reducing the technical cost of agricultural IoT can promote sustainable adoption of farmers. Increasing the integration of agriculture and the Internet of Things technology, increasing independent innovation of key equipment, reducing the cost of agricultural IoT equipment, and bringing greater profits to farmers are basic measures for the continuous adoption. And the numerical simulation proved it. This article provides strategic references for the development of smart agriculture sustainable development strategies in China.

\section{Appendix}

\section{A. Proof 1}

Lemma 1. If one point makes the trace of Jacobian matrix equal to zero in evolutionary dynamic system, this point is the saddle point [26].

The Jacobian matrix of the system is

$$
J=\left[\begin{array}{ll}
D_{1} & D_{2} \\
D_{3} & D_{4}
\end{array}\right]=\left[\begin{array}{cc}
\frac{\mathrm{d} \eta / \mathrm{d} t}{\mathrm{~d} \eta} & \frac{\mathrm{d} \eta / \mathrm{d} t}{\mathrm{~d} \mu} \\
\frac{\mathrm{d} \mu / \mathrm{d} t}{\mathrm{~d} \eta} & \frac{\mathrm{d} \mu / \mathrm{d} t}{\mathrm{~d} \mu}
\end{array}\right]
$$

where

$$
\begin{aligned}
D_{1}= & \frac{\mathrm{d} \eta / \mathrm{d} t}{\mathrm{~d} \eta} \\
= & \mu(1-2 \eta)\left(I_{2} \beta+I_{1} \varepsilon+\alpha_{2} c_{1}-I_{1} \varepsilon \gamma\right)-(1-2 \eta) \\
& \cdot\left(c_{1}-c_{2}-c_{N}-v_{F}-I_{1} \alpha_{1}+I_{2} \alpha_{1}+I_{1} \varepsilon-I_{2} \varepsilon\right) \\
= & \mu(1-2 \eta)\left(I_{2} \beta+I_{1} \varepsilon+\alpha_{2} c_{1}-I_{1} \varepsilon \gamma\right)-A(1-2 \eta), \\
D_{2}= & \frac{\mathrm{d} \eta / \mathrm{d} t}{\mathrm{~d} \mu}=-\eta(\eta-1)\left(I_{2} \beta+I_{1} \varepsilon+\alpha_{2} c_{1}-I_{1} \varepsilon \gamma\right), \\
D_{3}= & \frac{\mathrm{d} \mu / \mathrm{d} t}{\mathrm{~d} \eta}=\mu(\mu-1)\left(v_{G}+I_{2} \beta+I_{1} \varepsilon+\sigma R_{s}-I_{1} \varepsilon \gamma\right), \\
D_{4}= & \frac{\mathrm{d} \mu / \mathrm{d} t}{\mathrm{~d} \mu}=(1-2 \mu)\left[\left(v_{G}-c_{3}+I_{2} \beta\right)\right. \\
& \left.-\eta\left(v_{G}+I_{2} \beta+I_{1} \varepsilon+\sigma R_{s}-I_{1} \varepsilon \gamma\right)\right] .
\end{aligned}
$$

The trace of the Jacobian matrix is

$$
\begin{aligned}
\operatorname{Tr}(J)= & D_{1}+D_{4} \\
= & \mu(1-2 \eta)\left(I_{2} \beta+I_{1} \varepsilon+\alpha_{2} c_{1}-I_{1} \varepsilon \gamma\right) \\
& -A(1-2 \eta)+(1-2 \mu)\left[\left(v_{G}-c_{3}+I_{2} \beta\right)\right. \\
& \left.-\eta\left(v_{G}+I_{2} \beta+I_{1} \varepsilon+\sigma R_{s}-I_{1} \varepsilon \gamma\right)\right] .
\end{aligned}
$$

For $D\left(\eta^{*}, \mu^{*}\right)$,

$$
\left\{\begin{array}{l}
\mu^{*}=\frac{-\left(c_{2}-c_{1}+c_{N}+v_{F}+I_{1} \alpha_{1}-I_{2} \alpha_{1}-I_{1} \varepsilon+I_{2} \varepsilon\right)}{I_{2} \beta+I_{1} \varepsilon+\alpha_{2} c_{1}-I_{1} \varepsilon \gamma} \\
\eta^{*}=\frac{v_{G}-c_{3}+I_{2} \beta}{v_{G}+I_{2} \beta+I_{1} \varepsilon+\sigma R_{s}-I_{1} \varepsilon \gamma}
\end{array}\right.
$$

Substituting $\eta^{*}$ and $\mu^{*}$ into equation (26), we get $\operatorname{Tr}(J)=0$.

Thus, $D\left(\eta^{*}, \mu^{*}\right)$ is a saddle point.

Theorem 1 is proved.

\section{B. Proof 3}

$$
\begin{aligned}
S_{A}= & S_{\triangle C D B}-S_{\triangle A D C}=S_{1}-S_{3} \\
= & \frac{\left(c_{2}-c_{1}+c_{N}+v_{f}+I_{1} \alpha_{1}-I_{2} \alpha_{1}-I_{1} \varepsilon+I_{1} \varepsilon\right)}{2\left(I_{2} \beta+I_{1} \varepsilon+\alpha_{2} c_{1}-I_{1} \varepsilon \gamma\right)} \\
& +\frac{\left(v_{g}-c_{3}+I_{2} \beta\right)}{2\left(v_{g}+I_{2} \beta+I_{1} \varepsilon+b R_{s}-I_{1} \varepsilon \gamma\right)} .
\end{aligned}
$$

The derivatives of $S_{A}$ about cost subsidy $\alpha_{2}$ are

$$
\begin{aligned}
\frac{\partial S_{A}}{\partial \alpha_{2}}= & -\frac{c_{1}\left(c_{2}-c_{1}+c_{N}+v_{f}+I_{1} \alpha_{1}-I_{2} \alpha_{1}-I_{1} \varepsilon+I_{2} \varepsilon\right)}{2\left(I_{2} \beta+I_{1} \varepsilon+\alpha_{2} c_{1}-I_{1} \varepsilon \gamma\right)^{2}} \\
= & -\frac{c_{1}}{2\left(I_{2} \beta+\alpha_{2} c_{1}+I_{1} \varepsilon-I_{1} \varepsilon \gamma\right)} \\
& \times \frac{c_{2}-c_{1}+c_{N}+v_{f}+I_{1} \alpha_{1}-I_{2} \alpha_{1}-I_{1} \varepsilon+I_{2} \varepsilon}{I_{2} \beta+\alpha_{2} c_{1}+I_{1} \varepsilon-I_{1} \varepsilon \gamma}, \\
& \because I_{1} \varepsilon-I_{1} \varepsilon \gamma>0, \quad(1>\gamma>0), \\
& \therefore-\frac{c_{1}}{2\left(I_{2} \beta+\alpha_{2} c_{1}+I_{1} \varepsilon-I_{1} \varepsilon \gamma\right)}<0 \\
& \because \frac{c_{2}-c_{1}+c_{N}+v_{f}+I_{1} \alpha_{1}-I_{2} \alpha_{1}-I_{1} \varepsilon+I_{2} \varepsilon}{I_{2} \beta+I_{1} \varepsilon+\alpha_{2} c_{1}-I_{1} \varepsilon \gamma}<-\frac{1}{2} \\
& \therefore \frac{\partial S_{A}}{\partial \alpha_{2}}>0 .
\end{aligned}
$$

Theorem 3 is proved.

\section{Proof 4}

Because

$$
\left(\frac{\partial S_{A}}{\partial v_{f}}\right)=\frac{1}{2\left(I_{2} \beta+\alpha_{2} c_{1}+I_{1} \varepsilon-I_{1} \varepsilon \gamma\right)}>0,
$$

by increasing negative feedback of refusing technology, the system evolves toward point $C(1,1)$.

Theorem 4 is proved. 


\section{Proof 5}

$$
\begin{aligned}
& \because\left(I_{1} \varepsilon-I_{1} \varepsilon \gamma\right)>0, \quad(1>\gamma>0), \\
& \quad \therefore \frac{\partial S_{A}}{\partial v_{g}}=\frac{\left[c_{3}+b R_{s}+\left(I_{1} \varepsilon-I_{1} \varepsilon \gamma\right)\right]}{2\left[v_{g}+I_{2} \beta+b R_{s}+\left(I_{1} \varepsilon-I_{1} \varepsilon \gamma\right)\right]^{2}}>0 .
\end{aligned}
$$

So, the system evolves toward point $C(1,1)$ with the increase of positive feedback of the government.

Theorem 5 is proved.

\section{E. Proof 6}

$$
\begin{aligned}
& \because I_{1} \varepsilon-I_{1} \varepsilon \gamma>0, \quad(1>\gamma>0), \\
& \therefore \frac{\partial S_{A}}{\partial c_{N}}=\frac{1}{2\left(I_{2} \beta+\alpha_{2} c_{1}+I_{1} \varepsilon-I_{1} \varepsilon \gamma\right)}>0 .
\end{aligned}
$$

This means increasing price of chemical materials (such as pesticides and fertilizers) will promote the evolution to $C$ $(1,1)$.

Theorem 6 is proved.

\section{F. Proof 7}

Let

$$
\begin{aligned}
A= & I_{2} \beta+I_{1} \varepsilon-I_{1} \varepsilon \gamma+a_{2} c_{2}+a_{2} c_{N}+a_{2} v_{f} \\
& +I_{1} a_{1} a_{2}-I_{2} a_{1} a_{2}-I_{1} a_{2} \varepsilon+I_{2} \varepsilon \gamma, \\
S_{\square A D B C}= & S_{1}+S_{3} .
\end{aligned}
$$

The increase of $S_{\square A D B C}$ area means that the system is more likely to evolve to point $C$ or $A$.

If $A>0, \quad\left(\partial S_{\square A D B C} / \partial c_{1}\right)=-A /\left(2\left(I_{2} \beta+I_{1} \varepsilon+\alpha_{2} c_{1}-\right.\right.$ $\left.\left.I_{1} \varepsilon \gamma r\right)^{2}\right)<0$.

That is, the decrease of $c_{1}$ makes the system evolve in the direction of $C$ or $A$.

At this time, $\left(\partial S_{1} / \partial c_{1}\right)=-A /\left(2\left(I_{2} \beta+I_{1} \varepsilon+\alpha_{2} c_{1}-\right.\right.$ $\left.\left.I_{1} \varepsilon \gamma r\right)^{2}\right)>0$.

Therefore, reducing $c_{1}$ cannot make the system evolve to $C$ and then to $A(1,0)$.

Theorem 7 is proved.

\section{G. Proof 8}

The stability of the equilibrium point can be obtained by the eigenvalues of system's Jacobian matrix. The Jacobian matrix of the dynamical system is shown as follows:

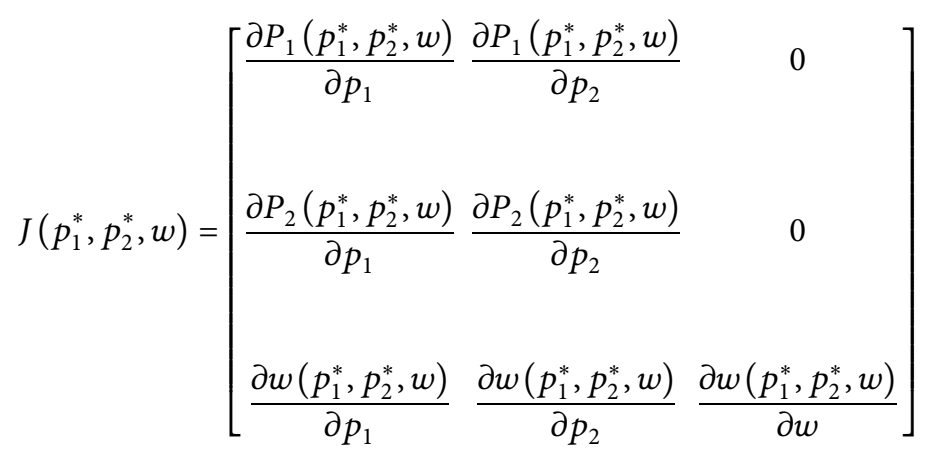

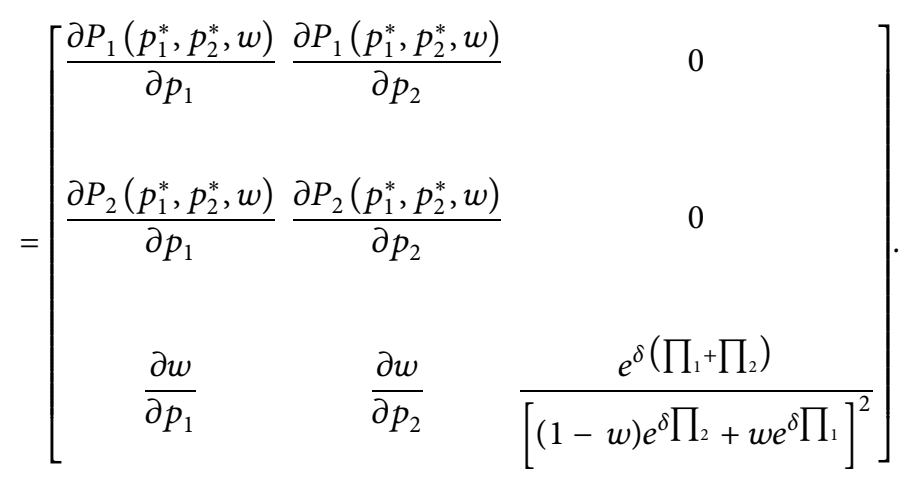


Its characteristic equation is

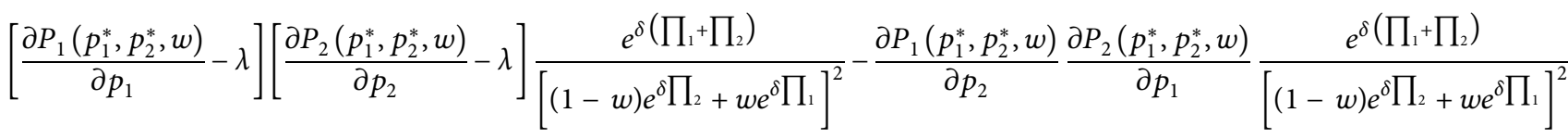

$$
\begin{aligned}
& =\left\{\left[\frac{\partial P_{1}\left(p_{1}^{*}, p_{2}^{*}, w\right)}{\partial p_{1}}-\lambda\right]\left[\frac{\partial P_{2}\left(p_{1}^{*}, p_{2}^{*}, w\right)}{\partial p_{2}}-\lambda\right]-\frac{\partial P_{1}\left(p_{1}^{*}, p_{2}^{*}, w\right)}{\partial p_{2}} \frac{\partial P_{2}\left(p_{1}^{*}, p_{2}^{*}, w\right)}{\partial p_{1}}\right\} \frac{e^{\delta\left(\prod_{1}+\prod_{2}\right)}}{\left[(1-w) e^{\left.\delta \prod_{2}+w e^{\delta} \prod_{1}\right]^{2}}\right.} \\
& =G \frac{e^{\delta\left(\prod_{1}+\prod_{2}\right)}}{\left[(1-w) e^{\left.\delta \prod_{2}+w e^{\delta} \prod_{1}\right]^{2}}\right.}
\end{aligned}
$$

In (G.2), $\left[\partial P_{1}\left(p_{1}^{*}, p_{2}^{*}, w\right) / \partial p_{1}-\lambda\right]\left[\partial P_{2}\left(p_{1}^{*}, p_{2}^{*}, w\right) / \partial p_{2}-\right.$ $\lambda]-\left(\partial P_{1}\left(p_{1}^{*}, p_{2}^{*}, w\right) / \partial p_{2}\right)\left(\partial P_{2}\left(p_{1}^{*}, p_{2}^{*}, w\right) / \partial p_{1}\right)$. is

The Jacobian matrix of the two-dimensional system

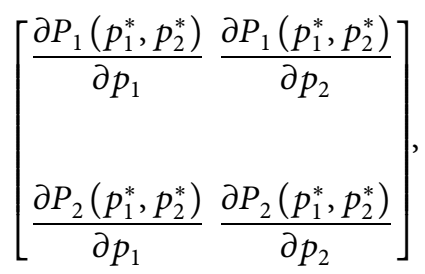

$G$ is the characteristic equation of the two-dimensional system which has the Nash Equilibrium solution. Therefore, $\lambda_{1}<1, \lambda_{2}<1$.

The characteristic equation of the three-dimensional system is $\left\{\left[\left(\partial P_{1}\left(p_{1}^{*}, p_{2}^{*}, w\right) / \partial p_{1}\right)-\lambda\right]\left[\left(\partial P_{2}\left(p_{1}^{*}, p_{2}^{*}, w\right) /\right.\right.\right.$ $\left.\left.\left.\partial p_{2}\right)-\lambda\right]-\left(\partial P_{1}\left(p_{1}^{*}, p_{2}^{*}, w\right) / \partial p_{2}\right) \quad\left(\partial P_{2}\left(p_{1}^{*}, p_{2}^{*}, w\right) / \partial p_{1}\right)\right\}$

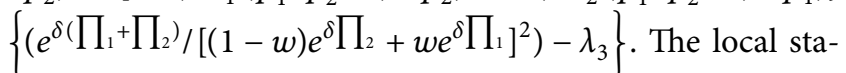
bility of the Nash equilibrium point can be obtained by the eigenvalues of system's Jacobian matrix. That is, if there is a eigenvalue whose modulus is greater than 1 , this equilibrium point is unstable [14].

When $\prod_{1}=\prod_{2}, w \in[0,1], \lambda_{3}=1$ is one of the eigenvalues of $J\left(p_{1}^{*}, p_{2}^{*}, w\right)$, and other eigenvalues $\lambda_{1}$ and $\lambda_{2}$ are all less than 1 . Thus, point $\left(p_{1}^{*}, p_{2}^{*}, w\right), w \in[0,1]$ is a stable equilibrium.

When $\prod_{1}>\prod_{2}, w=1, \lambda_{3}=e^{\delta\left(\prod_{1}+\prod_{2}\right) /\left[(1-w) e^{\delta} \prod_{2}+\right.}$

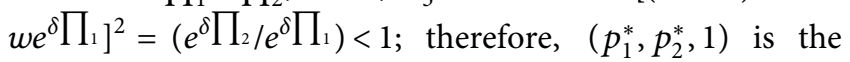
stable equilibrium point of the model.

When $\prod_{2}>\prod_{1}, w=0, \lambda_{3}=e^{\delta\left(\prod_{1}+\prod_{2}\right)} /\left[(1-w) e^{\delta \prod_{2}+}\right.$

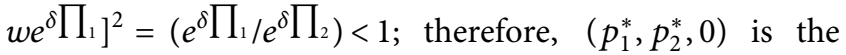
stable equilibrium point of the model.

Theorem 8 is proved.

\section{Data Availability}

The data used to support the findings of this study are included within the article.

\section{Conflicts of Interest}

The authors declare that they have no conflicts of interest.

\section{Acknowledgments}

This research was supported by the project funded by the China Postdoctoral Science Foundation (no. 2017M621077).

\section{References}

[1] K. Tang, A. Hailu, and Y. Yang, "Agricultural chemical oxygen demand mitigation under various policies in China: a scenario analysis," Journal of Cleaner Production, vol. 250, Article ID 119513, 2020.

[2] A. D. Boursianis, M. S. Papadopoulou, P. Diamantoulakis et al., "Internet of things (IoT) and agricultural unmanned aerial vehicles (UAVs) in smart farming: a comprehensive review," Internet of Things, Article ID 100187, 2020, In press.

[3] G. I. Ezenne, L. Jupp, S. K. Mantel, and J. L. Tanner, "Current and potential capabilities of UAS for crop water productivity in precision agriculture," Agricultural Water Management, vol. 218, pp. 158-164, 2019.

[4] A. P. Barnes, I. Soto, V. Eory et al., "Exploring the adoption of precision agricultural technologies: a cross regional study of EU farmers," Land Use Policy, vol. 80, pp. 163-174, 2019.

[5] S. T. Far and K. R. Moghaddam, "Impacts of the precision agricultural technologies in Iran: an analysis experts' perception \& their determinants," Information Processing in Agriculture, vol. 5, no. 1, pp. 173-184, 2018.

[6] S. Higgins, J. Schellberg, and J. S. Bailey, "Improving productivity and increasing the efficiency of soil nutrient management on grassland farms in the UK and Ireland using precision agriculture technology," European Journal of Agronomy, vol. 106, pp. 67-74, 2019.

[7] T. Yao, Z. Huang, and W. Zhao, "Are smart cities more ecologically efficient? evidence from China," Sustainable Cities and Society, vol. 60, Article ID 102008, 2020.

[8] Y. Liu, W. Han, Y. Zhang, L. Li, J. Wang, and L. Zheng, "An internet-of-things solution for food safety and quality control: a pilot project in China," Journal of Industrial Information Integration, vol. 3, pp. 1-7, 2016.

[9] F. Wu, Q. Du, J. Zhang et al., "Countermeasure study on transforming and upgrading traditional agriculture in Tianjin 
by Internet of Things," Journal of Chinese Agricultural Mechanization, vol. 39, no. 6, pp. 112-118, 2018.

[10] W. Li, B. Clark, J. A. Taylor et al., "A hybrid modelling approach to understanding adoption of precision agriculture technologies in Chinese cropping systems," Computers and Electronics in Agriculture, vol. 172, Article ID 105305, 2020.

[11] D. Xia, M. Zhang, Q. Yu, and Y. Tu, "Developing a framework to identify barriers of Green technology adoption for enterprises," Resources, Conservation and Recycling, vol. 143, pp. 99-110, 2019.

[12] H. P. Yuan and Y. Yang, "BIM adoption under government subsidy: technology diffusion perspective," Journal of Construction Engineering and Management, vol. 146, no. 1, Article ID 04019087, 2020.

[13] C. D. Lucia and P. Pazienza, "Market-based tools for a plastic waste reduction policy in agriculture: a case study in the south of Italy," Journal of Environmental Management, vol. 250, Article ID 109468, 2019.

[14] N. Zhao and F. Q. You, "Dairy waste-to-energy incentive policy design using Stackelberg-game-based modeling and optimization," Applied Energy, vol. 254, Article ID 113701, 2019.

[15] E. Sara, P. S. Fernando, F. C. Santos, V. Blass, J. M. Pacheco, and J. Portugali, "Paths to the adoption of electric vehicles: an evolutionary game theoretical approach," Transportation Research Part B: Methodological, vol. 113, pp. 24-33, 2018.

[16] T. Zhao and Z. Liu, "A novel analysis of carbon capture and storage (CCS) technology adoption: an evolutionary game model between stakeholders," Energy, vol. 189, Article ID 116352, 2019.

[17] Y. Shi, B. Han, and Y. Zeng, "Simulating policy interventions in the interfirm diffusion of low-carbon technologies: an agent-based evolutionary game model," Journal of Cleaner Production, vol. 250, Article ID 119449, 2020.

[18] M. Kopel, F. Lamantia, and F. Szidarovszky, "Evolutionary competition in a mixed market with socially concerned firms," Journal of Economic Dynamics \& Control, vol. 48, pp. 394-409, 2014.

[19] L. C. Baiardi, F. Lamantia, and D. Radi, "Evolutionary competition between boundedly rational behavioral rules in oligopoly games," Chaos, Solitons \& Fractals, vol. 79, pp. 204-225, 2015.

[20] G. I. Bischi, U. Merlone, and E. Pruscini, "Evolutionary dynamics in club goods binary games," Journal of Economic Dynamics \& Control, vol. 91, pp. 204-119, 2018.

[21] F. Lamantia and D. Radi, "Evolutionary technology adoption in an oligopoly market with forward-looking firms," Chaos: An Interdisciplinary Journal of Nonlinear Science, vol. 28, no. 5, Article ID 055904, 2018.

[22] F. Wu and J. H. Ma, "The equilibrium, complexity analysis and control in epiphytic supply chain with product horizontal diversification," Nonlinear Dynamics, vol. 93, no. 4, pp. 2145-2158, 2018.

[23] A. Naimzada and F. Tramontana, "Two different routes to complex dynamics in a heterogeneous triopoly game," Journal of Difference Equations and Applications, vol. 21, no. 7, pp. 553-563, 2015.

[24] C. H. Hommes, M. I. Ochea, and J Tuinstra, "Evolutionary competition between adjustment processes in cournot oligopoly: instability and complex dynamics," Dynamic Games and Applications, vol. 8, no. 4, pp. 822-843, ., 2018.

[25] N. Ahmad and P. Marina, "Complex dynamics in an evolutionary general equilibrium model," Discrete Dynamics in
Nature and Society, vol. 2018, Article ID 8471624, 13 pages, 2018.

[26] S. S. Askar, M. F. El-Wakeeland, and M. A. Alrodaini, "Exploration of complex dynamics for cournot oligopoly game with differentiated products," Complexity, vol. 2018, Article ID 6526794, 13 pages, 2018.

[27] P. Yu, L. Qian, X. Wu, Y. Zhao, and Y. Xiao, "Dynamics of Hotelling triopoly model with bounded rationality," Applied Mathematics and Computation, vol. 373, Article ID 125027, 2020.

[28] H. Garmani, D. A. Omar, M. E. Amrani, M. Baslam, and M. Jourhmane, "Analysis of a dynamics duopoly game with two content providers," Chaos Solitons \& Fractals, vol. 131, Article ID 109466, 2020.

[29] W. Zhou and X.-X. Wang, "On the stability and multistability in a duopoly game with $\mathrm{R} \& \mathrm{D}$ spillover and price competition," Discrete Dynamics in Nature and Society, vol. 2019, Article ID 2369898, 20 pages, 2019.

[30] J. Ma, Y. Hou, W. Yang, and Y. Tian, "A time-based pricing game in a competitive vehicle market regarding the intervention of carbon emission reduction," Energy Policy, vol. 142, Article ID 111440, 2020.

[31] V. R. Voller and F. P. Agel, "Moore's law and numerical modeling," Journal of Computational Physics, vol. 179, no. 2, pp. 698-703, 2002.

[32] N. R. John, J. H. G. Owen, E. Fuchs et al., "Digital atomic scale fabrication an inverse Moore's Law-a path to atomically precise manufacturing," Micro and Nano Engineering, vol. 1, pp. 1-14, 2018.

[33] B. P. Zeigler, Theory of Modeling and Simulation, Academic Press, Cambridge, MA, USA, 2nd edition, 2000.

[34] M. Castellani and M. Giuli, "An existence result for quasi equilibrium problems in separable Banach spaces," Journal of Mathematical Analysis \& Applications, vol. 425, no. 1, pp. 85-95, 2015.

[35] F. Si and J. Ma, "Complex dynamics in a triopoly game with multiple delays in the competition of green product level," International Journal of Bifurcation and Chaos, vol. 28, no. 2, Article ID 1850027, 2018.

[36] A. Matsumoto and Y. Nonaka, "Statistical dynamics in a chaotic Cournot model with complementary goods," Journal of Economic Behavior \& Organization, vol. 61, no. 4, pp. 769-783, 2006. 